Article

\title{
Temporal Evolution of Split-Injected Fuel Spray at Elevated Chamber Pressures
}

\author{
Gang $\mathrm{Wu}^{1,2,+}$, Xinyi Zhou ${ }^{2,+}$ (i) and Tie $\mathrm{Li}^{2, *}$ \\ 1 Merchant Marine College, Shanghai Maritime University, Shanghai 201306, China; wugang@shmtu.edu.cn \\ 2 State Key Laboratory of Ocean Engineering, Shanghai Jiao Tong University, Shanghai 200240, China; \\ zhou_xy@sjtu.edu.cn \\ * Correspondence: litie@sjtu.edu.cn \\ + These authors contributed equally to this work.
}

Received: 16 October 2019; Accepted: 7 November 2019; Published: 11 November 2019

check for updates

\begin{abstract}
For reducing soot and NOx emissions, an effective method is to apply split injection strategies. In this research, characteristics of split injection were investigated by applying the pilot-main injection strategy and main-post injection strategy. The injection mass of fuel with the two strategies was measured by an in-house fuel injection rate test system based on the Bosch method. The development of spray tip and tail penetrations, as well as the evolvement of the spray angle when applying these two injection strategies, were explored by employing the high speed shadowgraphy at various injection pressures and surrounding gas densities. The results indicate the tail penetration rate of spray has no relation to the fuel injection pressure. However, the increased injection pressure causes a faster penetration development in the spray tip position. It was also found that the spray tip penetration rate of the second spray is slightly slower than that of the first spray at the beginning stage of injection, but it was significantly larger than the first one at the later stage.
\end{abstract}

Keywords: split injection; diesel engine; spray mixture formation processes; injection rate

\section{Introduction}

An effective method for reducing soot and NOx emissions of internal combustion engines is applying split injection strategies [1]. Studies show that split injections can increase the mean effective pressure [1], promote a homogeneous mixing process [2], and reduce emissions [3]. Wang et al. [4] revealed that the reduced penetration length and impingement probability were beneficial to the emissions reduction. Additionally, the split injection strategy can also affect the ignition timing. This is essential for improving the combustion process. According to Carlucci [5], the ignition delay was reduced when using split injection strategies, which means more flexible control for the start of ignition and a more effective method to control emissions [6]. In addition, some other studies also revealed that split injection strategies can improve the combustion efficiency [7] and reduce engine noise [8]. Therefore, it would be useful to study the spray evolution of split injections in an inert environment in the absence of combustion.

Compared to the single injection, the spray characteristics and influencing factors of split injections tend to be more complex. For example, Kourosh [9] described that the first injection plume has a large similarity to the single injection plume in their research, while the second one had a significant difference compared to the result of single injection. According to Kourosh, when the residence time was long enough, no difference in plume speed was found. It can be predicted that the interval between the two split injection events could be an important factor affecting the split injection characteristics. Han et al. [10] also found similar results regarding the dwell interval and stated that the reason is that the duration of the dwell interval will affect the initial pressure at the beginning, which will also affect 
the average pressure of the main injection event. These changes in pressure also continue to affect the injection quality further, which, in turn, leads to changes in the spray characteristics. Hadadpour et al. [11] reported that it is crucial to focus the current research on the spray characteristics and combustion characteristics. They illustrated that the basic physics involved in the split injection strategy are complex and came up with some key factors about the split injection effects, such as intensive mixing [12], combustion temperatures [13], and injection duration effects [14]. Through a large-eddy simulation study, they found that the second injection of the spray changed the mixture near the nozzle, and it is helpful for improving the spray mixture formation processes. This view is consistent with the theory that proposed and developed by Hu [15] and Huang et al. [16]. According to their theory, it is the mutual influence of the split plumes that results in a strong disturbed motion when the sprays develop, and the large eddy is enhanced by the large amount of air entrainment and the penetration of upcoming spray into the former. To a certain extent, the dispersion performance of fuel droplets conduce to illustrate the effect of split injection on the spray disturbance. Wang et al. [17] reported that the number of splits in each injection also exerts an influence on the injection characteristics. However, when considering the number of splits, it requires special attention to the possible changes in injection pressure. In another study [18], they also investigated the break-up of droplets and the spray area through an optical test system in a pressure vessel. The results indicated that the Sauter mean diameter (SMD) in the spray of split injection is larger than that of the single injection. This is because of the insufficient opening of the needle valve, resulting from the shortened injection pulse width when applying the split injection strategy, which caused the highest effective pressure not to be established. On the other hand, the hypothetical collision effect between spray droplets in the split-injected fuel spray can not only explain the reason for the increased SMD, which also illustrates the complexity of the split spray characteristics. In addition, it has also been confirmed [10] that the ratio factors of the injected fuel mass at the pilot injection stage to the mass at the main injection stage is critical because it affects the developed boundaries of the spray [19]. The spray mixture formation processes also depend on the injection mass ratio [20]. At the same time, it will affect the subsequent exothermic process as well [21]. For this reason, a more detailed research on different injection mass ratios for the better applications of split injection strategies deserves to be carried out.

For one-split injection strategies, there are mainly two basic applications, that is, the pilot-main injection strategy and the main-post injection strategy. For the pilot-main injection strategy, a small portion of pilot fuel was injected into the cylinder to create a partially premixed mixture. By the formation of such mixture, the ignition delay of the injected fuel in the main injection stage will be shortened and the maximum pressure rise rate will be reduced as well [10]. Hiroshi et al. [22] found that the pilot injection can reduce the pressure rise rate of the main injection, as well as the ignition delay period. In fact, by dividing the fuel injection into small pilot injections, it can reduce the magnitude of the premixed combustion as well as the local in-cylinder temperature, which will favor a reduction in NOx emissions [23]. Post-injection is also an injection strategy that is commonly used to reduce soot particle emissions. Zhuang et al. [24] studied the emissions and engine performance by using split injection strategies in a direct injection engine. The study found that it can reduce NOx and soot emissions at a certain injection timing no matter the pilot-injection or the post-injection strategies. Furthermore, some split injection strategies could lead to emission effects that were not optimal. Yao et al. [25] studied the pilot injection and the post injection strategies with a heavy-duty diesel engine. The study confirmed that the pilot injection and the post injection strategies can reduce engine emissions of NOx and soot, while the increase in CO appears with the pilot injection strategy. Chen et al. [26] applied a pre-injection strategy with a short pre-injection and a long main injection which resulted in the increased soot emissions, although the $\mathrm{NOx}, \mathrm{CO}$, and unburned hydrocarbon (UHC) emissions being reduced. Han et al. [27] also proved that optimized split injection strategies can significantly reduce soot emissions, but under some specific conditions it can increase soot emissions.

From the above, applying split injection strategies has the ability to improve the spray mixture formation and combustion processes as well as the engine performance and emissions, but there are 
still a great deal of optimization works for the split injection strategies. At the same time, although the main macroscopic characteristics of the spray when applying a split injection strategy are considered to be important and complicated, it is necessary to realize that the underlying physical processes of split injection are not fully investigated and understood. This is because the penetration and break-up of fuel droplets have undergone a more complicated variation in the split injection strategies. In particular, the effect and interaction of various injection pressures and surrounding gas densities on each split-injected spray remains unclear, as well as the spray development under different injection strategies. On the other hand, most of the previous studies regarding split-injected fuel sprays did not pay much attention to the spray tail penetration, although it is very important for understanding the splitting injection strategies. There is an interaction between the tip penetration of the second spray and the tail penetration of the first spray, which will affect the mixture formation processes of the spray.

Therefore, with the purpose of studying the split injection effect, this paper focuses on the split-injected spray characteristics by applying two split injection strategies. Firstly, the fuel injection rate with the pilot-main injection strategy and main-post injection strategy were investigated. Then, the spray mixture formation processes based on these two strategies were observed with ultra-high speed shadowgraphy in the steel volume vessel at various injection pressures and surrounding gas densities. Finally, the interaction between the first and second sprays with the split-injection strategy is discussed.

\section{Experimental Setup}

A designed system for the test of the fuel injection rate is shown in Figure 1. The system was designed by employing a set of long tubes. The main components in the system are: a pressure gauge (shown as 1), a vessel (2), a ball valve (3), a nozzle (4), a pressure detector (5), drain valve (6), and a set of long tubes (7). Fuel was discharged into the long curved tube from the injector, and the pressure wave was gauged by a KISTLER 6125C(KISTLER, Winterthur, Switzerland) piezoelectric sensor. The signal was amplified by a KISTLER 5018A (KISTLER, Winterthur, Switzerland) charge amplifier. These data were then collected by an NI (National Instruments, Austin, TX, USA) data collection information board. The fuel injection rate can be calculated on the foundation of Bosch's method that can be expressed as Equation (1):

$$
P=a \cdot \rho_{f} \cdot u
$$

where $P$ is the pressure wave obtained by the piezoelectric sensor, $a$ is the speed of sound in fuel, $\rho_{f}$ is the fuel density, and $u$ is the fuel flow rate. The detailed methods can be found in [28]. Moreover, through the integral calculation for the injection rate, the total injection mass of fuel during the injection period can be acquired.

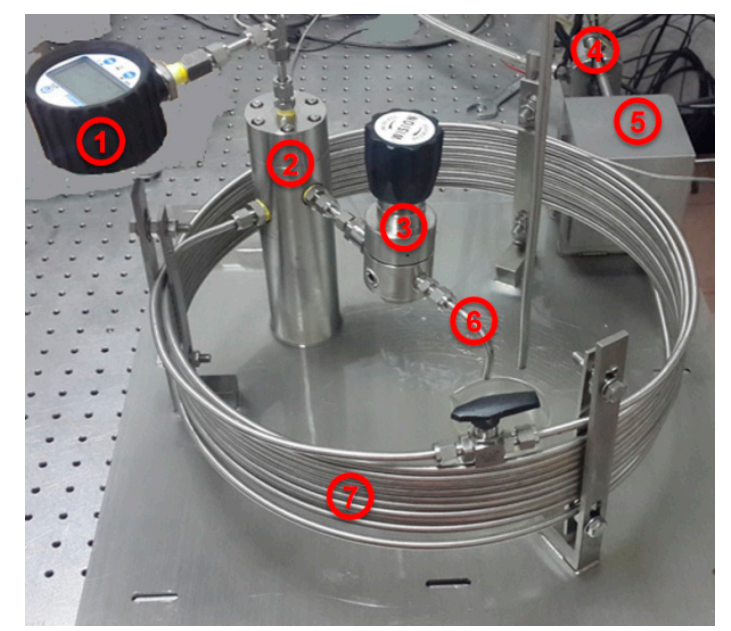

Figure 1. The designed test system for injection rate based on the long tube method. 
Figure 2 depicts the basic visualization experimental system setups for measuring the spraying characteristics. This system is mainly composed of a constant volume chamber, xenon lamp, high-speed CMOS (Complementary Metal Oxide Semiconductor) camera, pinhole, and concave mirror. Through using a Z-type light path layout, high-speed shadowgraphy was executed to reflect the spray morphology. One side of the Z-type light path is the illumination system, and the other side is a high-speed imaging system. The light source is a Newport $66984300 \mathrm{~W}$ xenon lamp. After passing through a pinhole, the point light source illuminates a concave mirror to form parallel light, which increases the illumination area of the spray within the chamber. After that, the parallel light passed through a concave mirror and was then refocused into a point. An NAC HX-6 high-speed CMOS camera (Photron, Kyoto, Japan), with a capability to capture images at speeds of 650,000 fps, is positioned at the focus point for sharper visualization imaging. The gas temperature in the chamber is measured by an OMEGA TJ36-CAXL K-type thermocouple probe (Spectris, Philadelphia, NJ, USA). The instantaneous pressure in chamber is measured by employing a Kistler 6054B pressure detector. A more detailed specification about the injection rate and spray test system can be found in our earlier studies $[29,30]$.

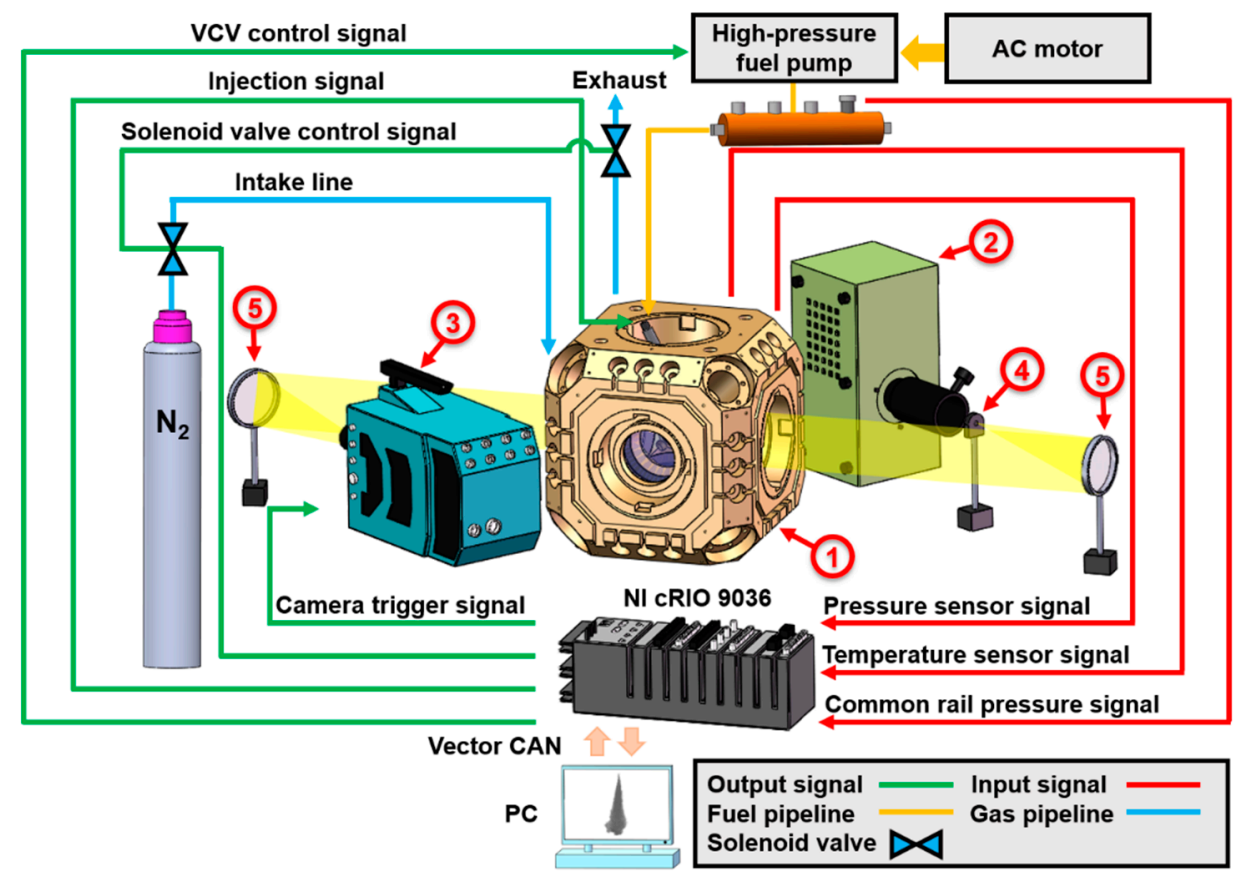

Figure 2. Visualization of the experimental system setup for determining the spray characteristics. 1:

Constant volume chamber; 2: xenon lamp; 3: high-speed CMOS camera; 4: pinhole; 5: concave mirror.

In order to study the tail penetration of the split-injected fuel sprays, it is necessary to first define the spray characteristics. Figure 3 illustrates the definitions of the spray characteristics. $\alpha$ represents the spray angle. $A_{\mathrm{s}}$ is the definition of spray area. As $S_{L} / 2$ is defined as the half length of the entire spray, $A_{s, S L / 2}$ is the definition of the upper spray area at the half spray length. The various positions of the entire spray jet are also shown in Figure 3 by the uppercase alphabet. $O$ represents the outlet position of the injector hole. $T$ is the highest point for the entire spray jet. $H$ locates in the lowest point in the spray jet area. Therefore, the entire spray length, as well as the tip penetration length and tail penetration length of the spray, could be described as the distance of $\mathrm{TH}, \mathrm{OH}$, and $\mathrm{OT}$, respectively. 


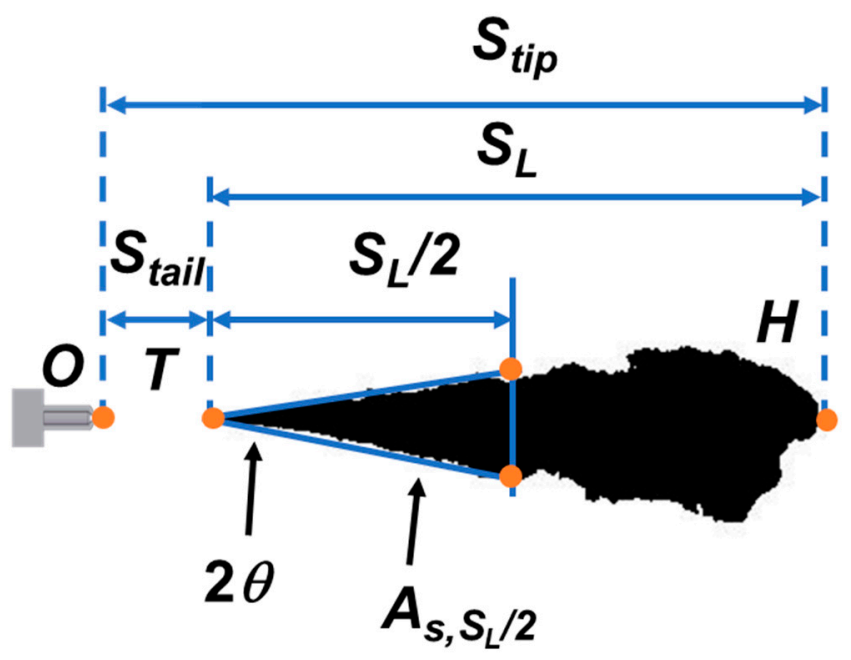

Figure 3. Definitions of the spray characteristics.

When considering the transient spray development at a certain time $t$, the spray length $S_{L}(t)$ can be expressed as Equation (2):

$$
S_{L}(t)=S_{\text {tip }}(t)-S_{\text {tail }}(t)
$$

$\theta$ is half of the spray angle $\alpha$. The half angle of the spray can be calculated as Equation (3):

$$
\theta=\tan ^{-1}\left[\frac{A_{S, S_{L} / 2}}{\left(S_{L} / 2\right)^{2}}\right]
$$

According to the definitions above, there is a constant value for the spray length and spray tip penetration before the EOI (End of Injection). The image processing and the threshold were established by using the method proposed by Siebers [31]. A code already been written in Matlab software (2016a, MathWorks, Natick, MA, USA) was employed to calculate the spray angle and the spray tip penetration and tail penetration as well.

In this study, the fuel to be tested is standard D100 diesel oil with a density of $818 \mathrm{~kg} / \mathrm{m}^{3}$, a surface tension of $28.5 \mathrm{mN} / \mathrm{m}$, a kinematic viscosity of $3.35 \mathrm{~mm}^{2} / \mathrm{s}$ at $20^{\circ} \mathrm{C}$, a latent heat of evaporation of $270 \mathrm{~kJ} / \mathrm{kg}$, and a low calorific value of $42.8 \mathrm{MJ} / \mathrm{kg}$. Table 1 shows the specific conditions for the injection rate test. Table 2 shows the specific measurement conditions for the fuel spray. Based on suggestion [32], the value of the surrounding gas pressure in the test system for injection rate was adjusted as $4.0 \mathrm{MPa}$. In this research, every measurement was duplicated five times to elevate the accuracy of the test results. Energized durations and intervals for two injection strategies are shown in Table 3.

Table 1. Conditions for the injection rate test.

\begin{tabular}{cc}
\hline Parameter & Value \\
\hline Temperature of fuel $(\mathrm{K})$ & 293 \\
Density of fuel $\left(\mathrm{kg} / \mathrm{m}^{3}\right)$ & 819 \\
Number of nozzle & 1 \\
Type of nozzle & Mini sac \\
Diameter of nozzle $(\mathrm{mm})$ & 0.14 \\
Length of nozzle $(\mathrm{mm})$ & 0.64 \\
Injection pressure $(\mathrm{MPa})$ & $90.0,120.0,150.0$ \\
Injection strategy & pilot-main, main-post \\
Surrounding gas pressure $(\mathrm{MPa})$ & 2.0 \\
Surrounding gas temperature $(\mathrm{K})$ & 293 \\
\hline
\end{tabular}


Table 2. Conditions for the fuel spray.

\begin{tabular}{cc}
\hline Parameter & Value \\
\hline Fuel temperature $(\mathrm{K})$. & 293 \\
Fuel density $\left(\mathrm{kg} / \mathrm{m}^{3}\right)$ & 819 \\
Hole number & 1 \\
Number of hole & Mini sac \\
Diameter of hole $(\mathrm{mm})$ & 0.14 \\
Length of hole $(\mathrm{mm})$ & 0.64 \\
Injection pressure $(\mathrm{MPa})$ & $90.0,120.0,150.0$ \\
Injection strategy & pilot-main, main-post \\
Imaging speed $(\mathrm{fps})$ & 27,000 \\
Surrounding gas pressure $(\mathrm{MPa})$ & $1.31,1.57,1.83$ \\
Surrounding gas density $\left(\mathrm{kg} / \mathrm{m}^{3}\right)$ & $15,18,21$ \\
Surrounding gas temperature $(\mathrm{K})$ & 293 \\
Surrounding gas & Nitrogen \\
\hline
\end{tabular}

Table 3. Conditions for the energization.

\begin{tabular}{ccc}
\hline Injection Strategies & Pilot-Main & Main-Post \\
\hline The first energized duration (ms) & 0.40 & 0.65 \\
The energized interval (ms) & 1.70 & 3.34 \\
The second energized duration (ms) & 0.65 & 0.40 \\
\hline
\end{tabular}

\section{Results and Discussion}

\subsection{Injection Rate and Injection Mass}

When applying the pilot-main injection strategy, the results of the injection rate under various injection pressures are shown in Figure 4. The injection pressures were set as 90, 120, and $150 \mathrm{MPa}$, respectively. The coordinate of the transverse $\mathrm{X}$-axis represents the energized time since the beginning of the trigger. The left $\mathrm{Y}$-axis shows the injection rate. The right $\mathrm{Y}$-axis represents the amplitude of the current. The two events denote to the pilot injection stage and main injection stage, respectively. As shown in Figure 4, the injection rate increases obviously with the injection pressure increasing. This is because the increased fuel injection pressure can enlarge the pressure difference through the nozzle, resulting in the increased injection rate. When applying the main-post injection strategy, the fuel injection rate under different injection pressures are shown in Figure 5. In Figures 4 and 5, the duration time of the current signal is shorter than the actual fuel injection duration. This phenomenon is caused by the control characteristics and injector characteristics. Since the opening of the needle is controlled by the current signal, the starting time of each injection is nearly to the same when at the same current regardless of the different injection pressures. However, at the increased injection pressure, the needle lift increases, which prolongs the fallback time of the needle valve. Therefore, the duration of the injection will be extended with the increased injection pressure. 


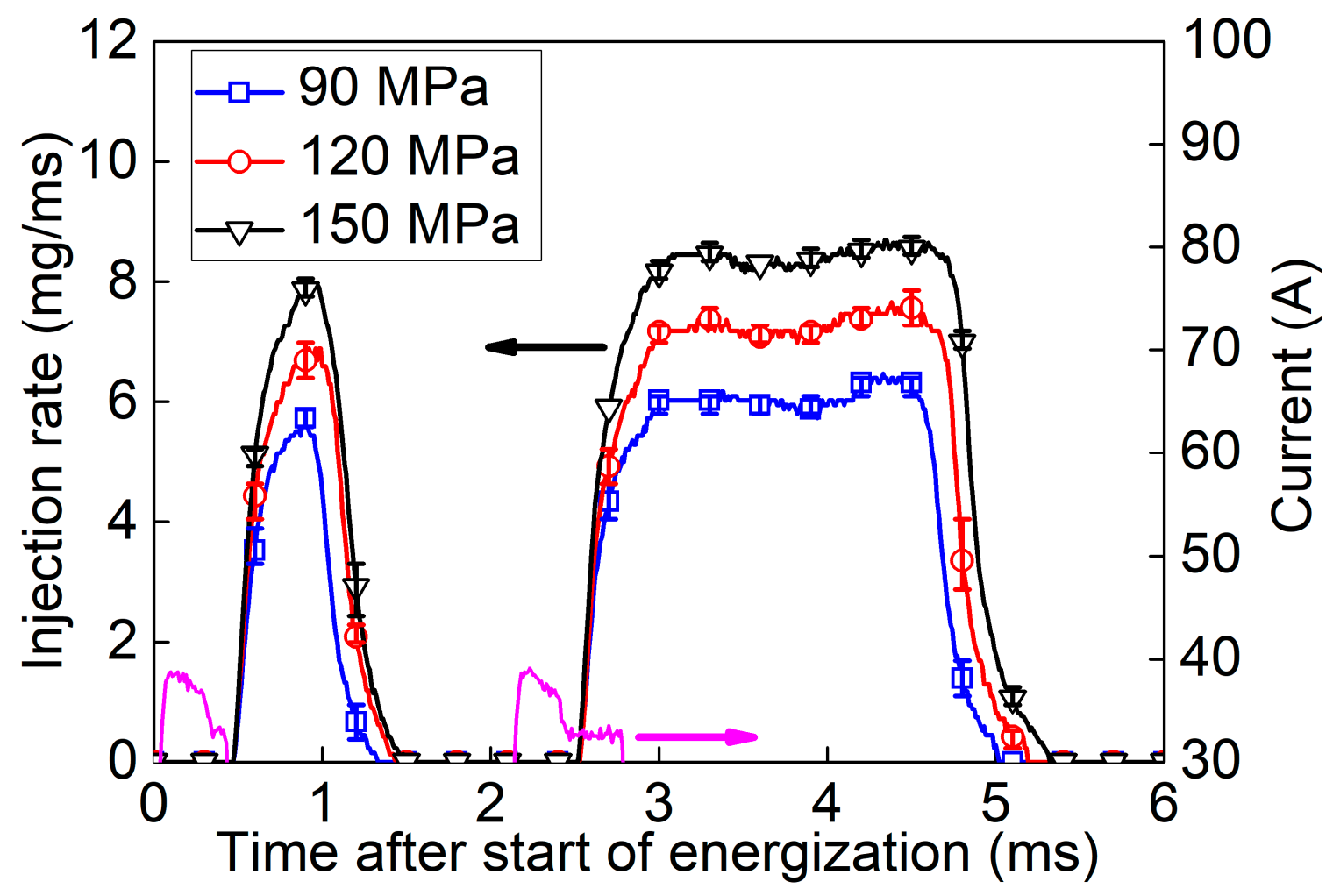

Figure 4. Results of injection rate for the pilot-main strategy.

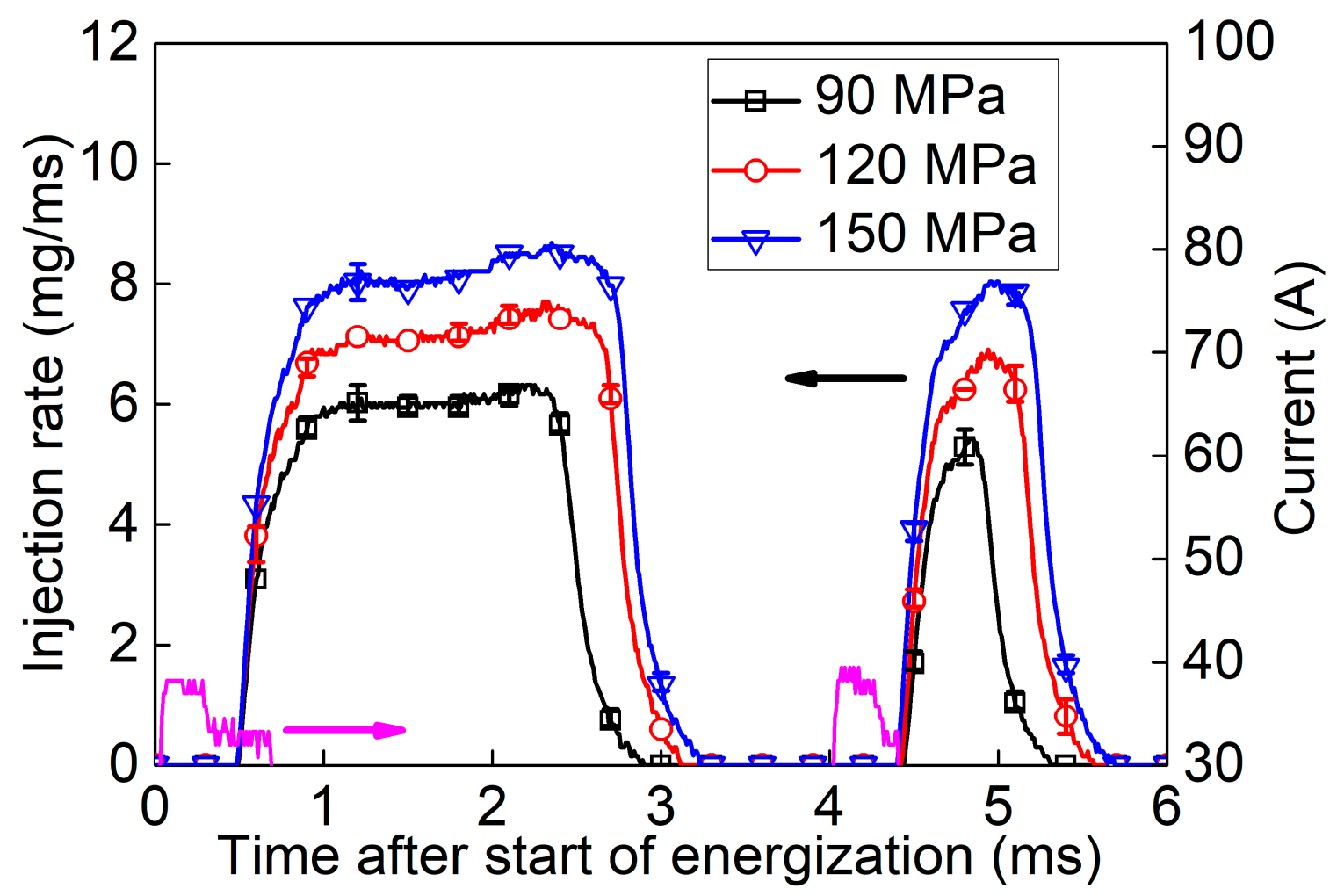

Figure 5. Results of injection rate for the main-post strategy.

The results also show that the injection rate increases with the increasing injection pressure. An integral calculation is used to obtain the total fuel injection amount during the injection processes. The results of the fuel injection mass with the pilot-main injection strategy and main-post injection 
strategy are shown in Figures 6 and 7, respectively. With the increased injection pressure, the injection mass increases. Gravimetric measurement validating the accuracy of the Bosch-type fuel injection rate test system has been conducted in a previous study [29].

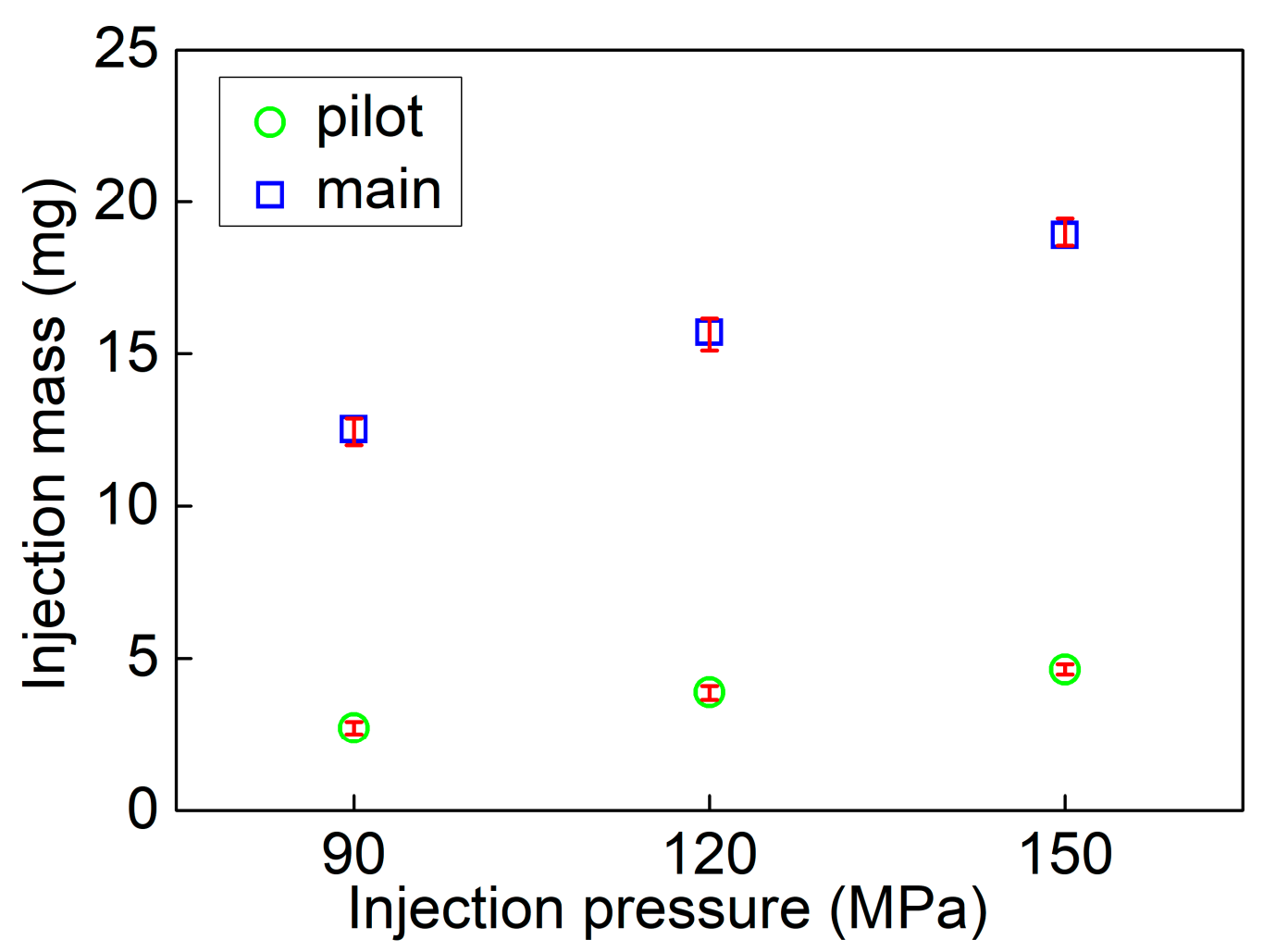

Figure 6. Results of each injection mass for the pilot-main strategy.

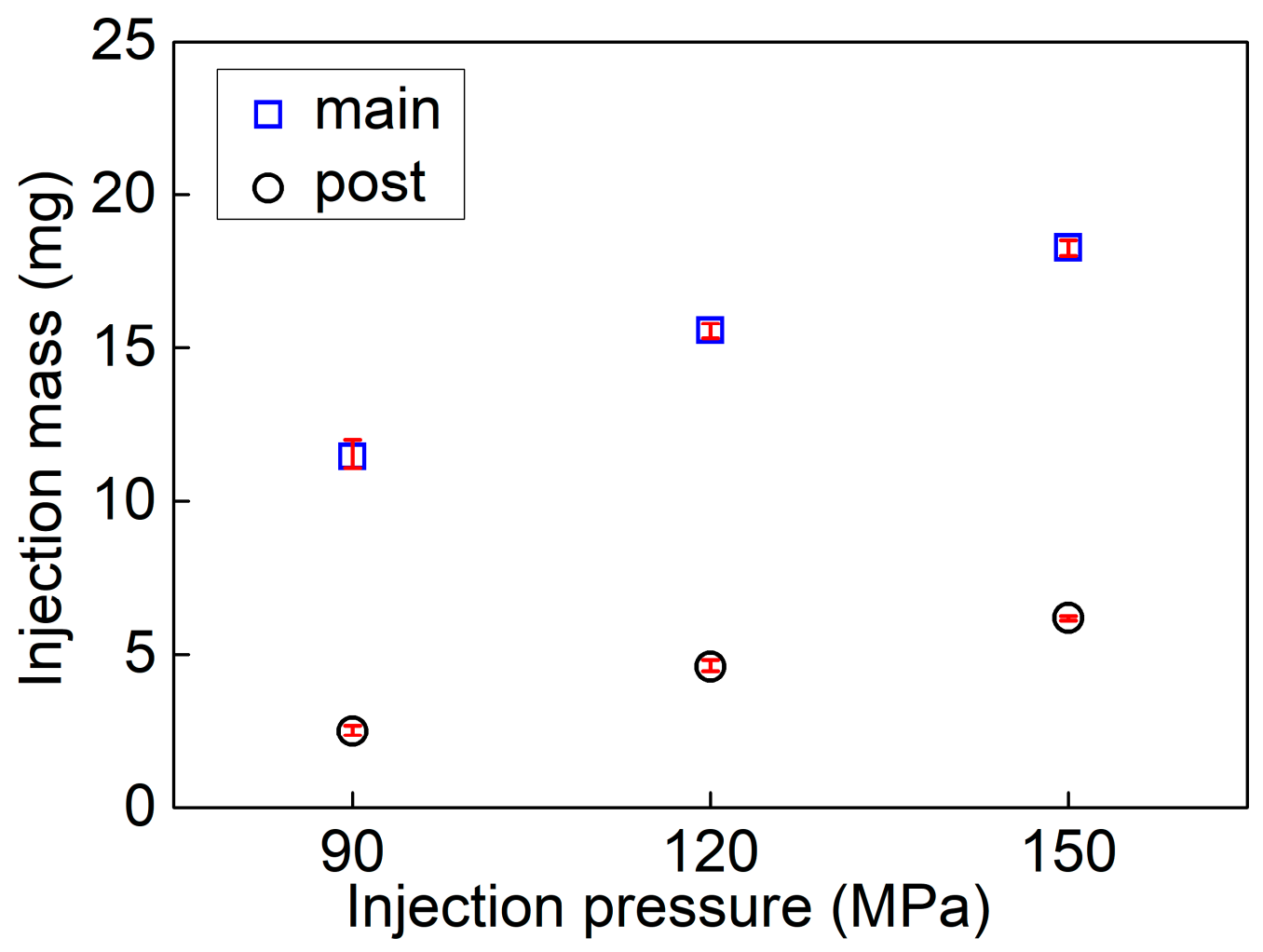

Figure 7. Results of each injection mass for the main-post strategy. 


\subsection{Split-Injected Spray}

Figure 8 shows the instantaneous spray development under the two different injection strategies. The upper part of image is the spray progressed plume by applying the pilot-main injection strategy and the lower part is the spray by applying the main-post injection strategy. In this test, the hole diameter of fuel injector was chosen as $0.14 \mathrm{~mm}$. The fuel injection pressure was kept at $90 \mathrm{MPa}$ and the environmental density was adjusted to be $15 \mathrm{~kg} / \mathrm{m}^{3}$. As can be seen, the spray penetrates very quickly at the initial stage of injection for each splitted spray, then it decreases as time elapses, particularly after the EOI. These experimental results are in agreement with the results of previous studies made by the other researchers $[33,34]$. After the EOI, the kinetic energy of the fuel no longer increases, and the resistance is the reason for the decreased penetration rate. At the same time, compared with the penetration rate for the tip position, the penetration rate is far slower at the tail position. Moreover, the tip penetration rate of the first splitted spray when applying the pilot-main injection strategy is slower than that of applying the main-post injection strategy. This is due to the shorter energizing and lower injection mass of the former case, which means lower momentum and velocity. For the same reason, the tip penetration rate of the second splitted spray when applying the pilot-main injection strategy is faster than that of the main-post injection strategy. In addition, after observing the image carefully, it can also be found that there is some turbulence involving the sudden changes in spray structures, although the range of variation is not obvious, just along the spray edges during the injection. For instance, in the time from $1.0 \mathrm{~ms}$ to $2.0 \mathrm{~ms}$ in the pilot-main strategy and the time from $1.0 \mathrm{~ms}$ to $2.0 \mathrm{~ms}$ in the main-post strategy it seems that the existence of the turbulent structure of the spray is easier after EOI than that of the injection period. There are some inconsistent views on the interpretation of this issue. According to $\mathrm{Hu}$ et al. [15], along the boundaries of the spray, the surrounding gas will be swallowed into the gap between the large structures. However, Huang et al. [16] believed the reason for this 'wave-like' structure is a result of the lack of following entrainment force. Therefore, a detailed study of the characteristics of the split sprays needs to be conducted.

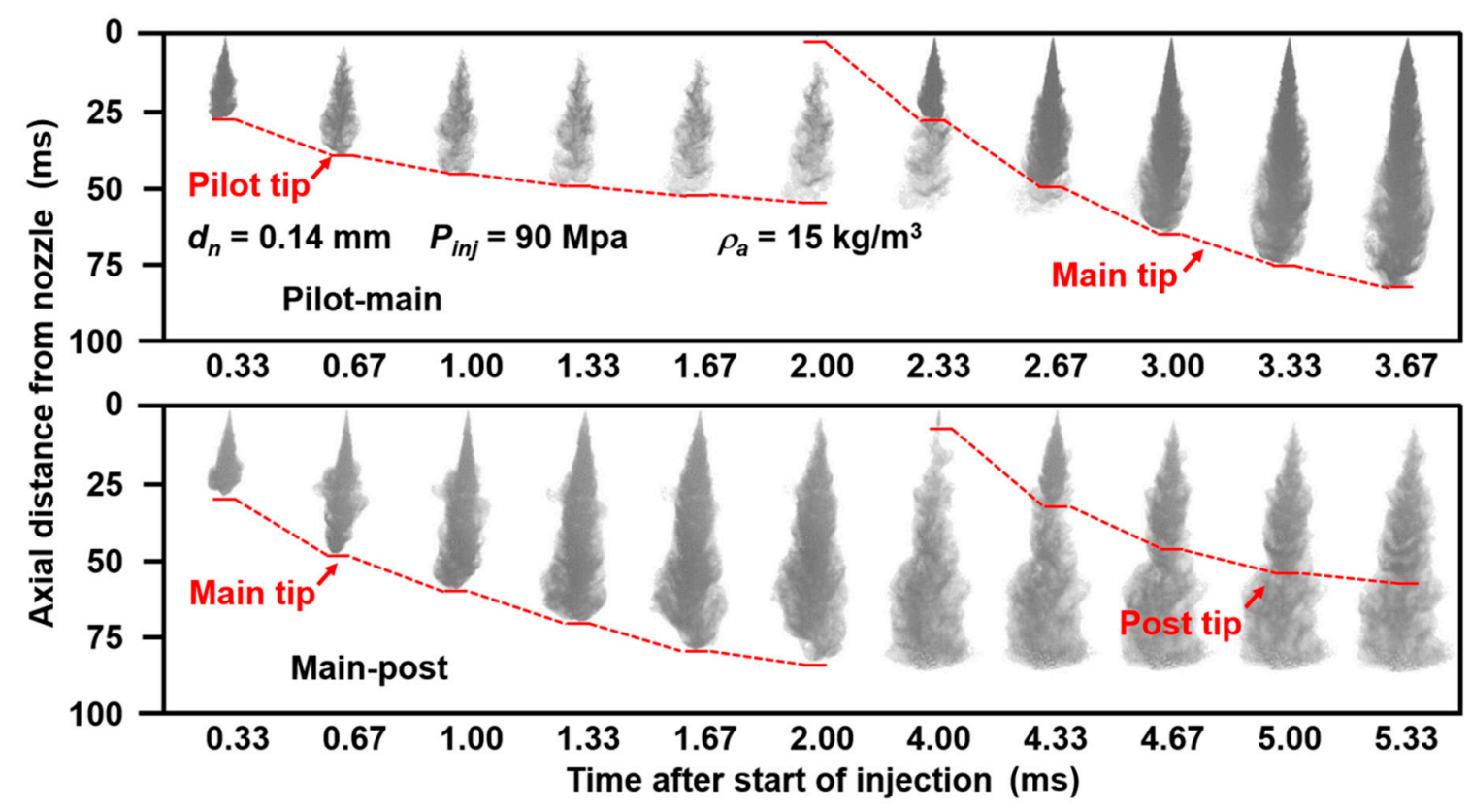

Figure 8. The instantaneous spray development for the pilot-main and main-post injection strategies.

Experimental results of penetrations when applying the pilot-main injection strategy under various injection pressures are plotted in Figure 9. The surrounding gas density was kept at $15 \mathrm{~kg} / \mathrm{m}^{3}$, and the injection pressure varies, at 90, 120, and $150 \mathrm{MPa}$, respectively. For the purpose of better visual observation, the solid and hollow symbols are plotted to distinguish the results. The solid symbol 
represents that the spray was still in the injection process, and the hollow symbol represents the spray after EOI. At the initial stage of the injection before EOI, there is a very fast penetration rate of the spray in the tip position. With the time elapsing, the spray tip penetrates with a declining rate compared to the previous moment. The reason for the dropped penetration rate in the tip position is the existence of momentum exchange between the environmental air and the fuel droplets after break-up. Then, after the EOI, the tip penetration reduces its growth trend to a gentler slope. Compared to the tip rate, the penetration rate in the tail position is far slower, resulting in the significant extension of the spray. This is because, at the end of the injection, the pressure of the nozzle sac is much lower than the injection pressure. The results also indicate that the increased injection pressure tends to cause an increase in the tip penetration rate for the spray. There is an obvious ascent of the spray tip penetration rate under high injection pressure. On the other hand, no obvious differences were found in the spray tail penetration under various fuel injection pressures. Generally, the results indicate that there is an obvious increase in the spray tip penetration rate with the increased injection pressure.

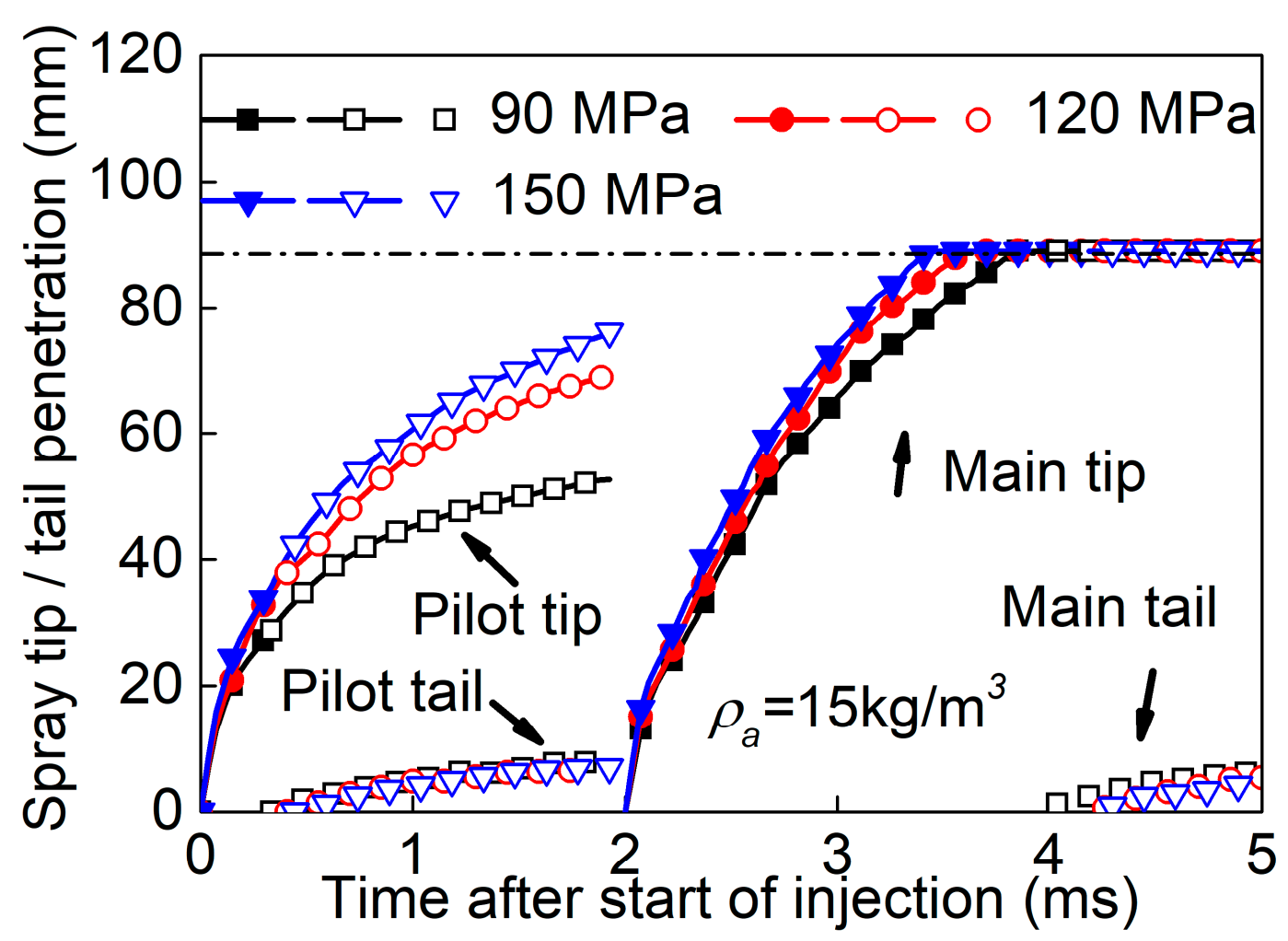

Figure 9. Results of spray tip and tail penetrations when applying the pilot-main injection strategy under various injection pressures.

Figure 10 shows the spray angle evolvements for the same condition. Compared to the variation of penetration, the increased injection pressure does not cause too much variation in the spray angle. In general, in the initial stage of fuel injection, there is a drastic change in the spray angle, which is consistent with the results of Doudou [35]. 


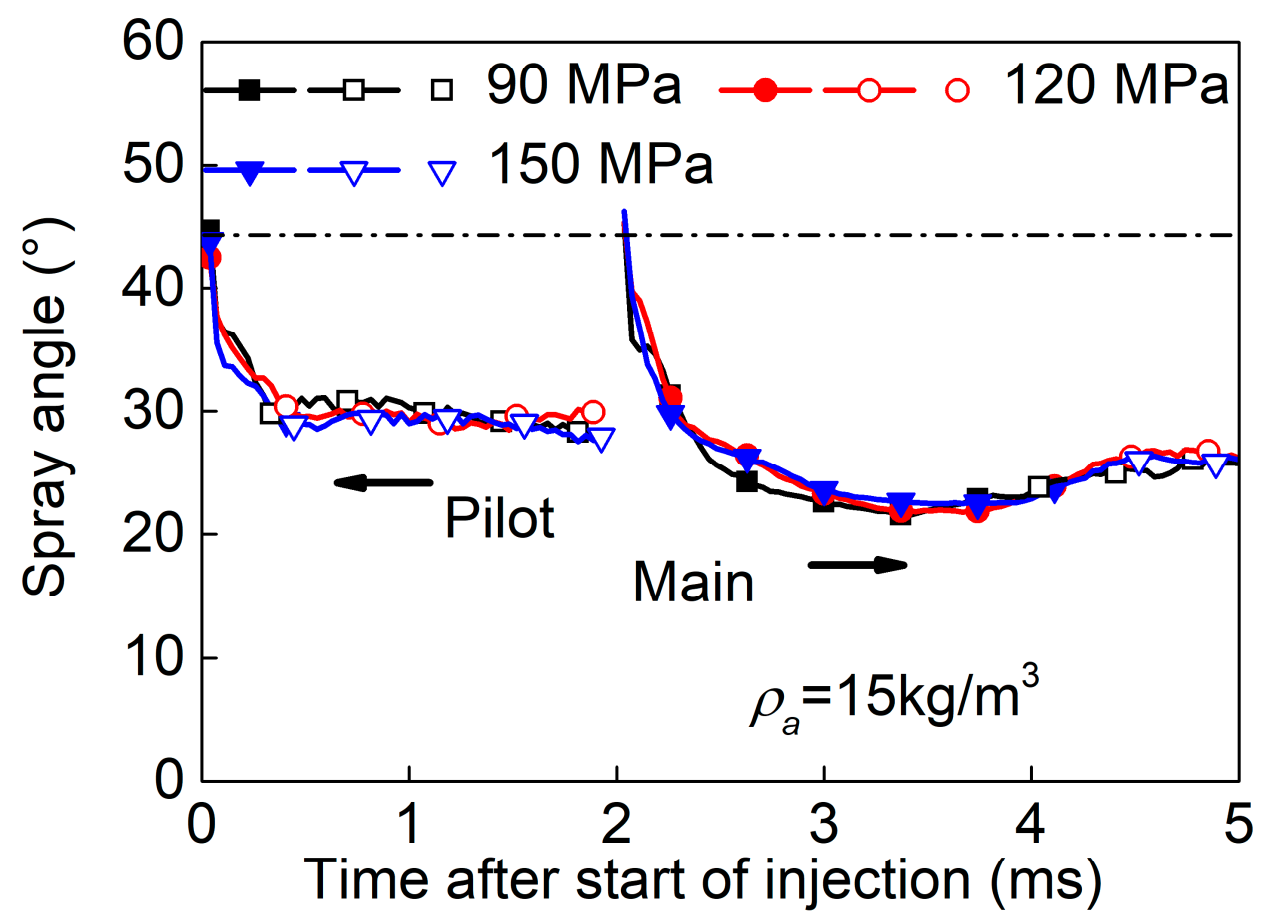

Figure 10. The spray angle evolvements when applying the pilot-main injection strategy under various injection pressures.

Figure 11 shows the results of spray tip and tail penetrations when applying the main-post injection strategy under various injection pressures. The surrounding gas density and injection pressures were the same as above. Similarly, no significant differences were found in the spray tail penetration at different fuel injection pressures.

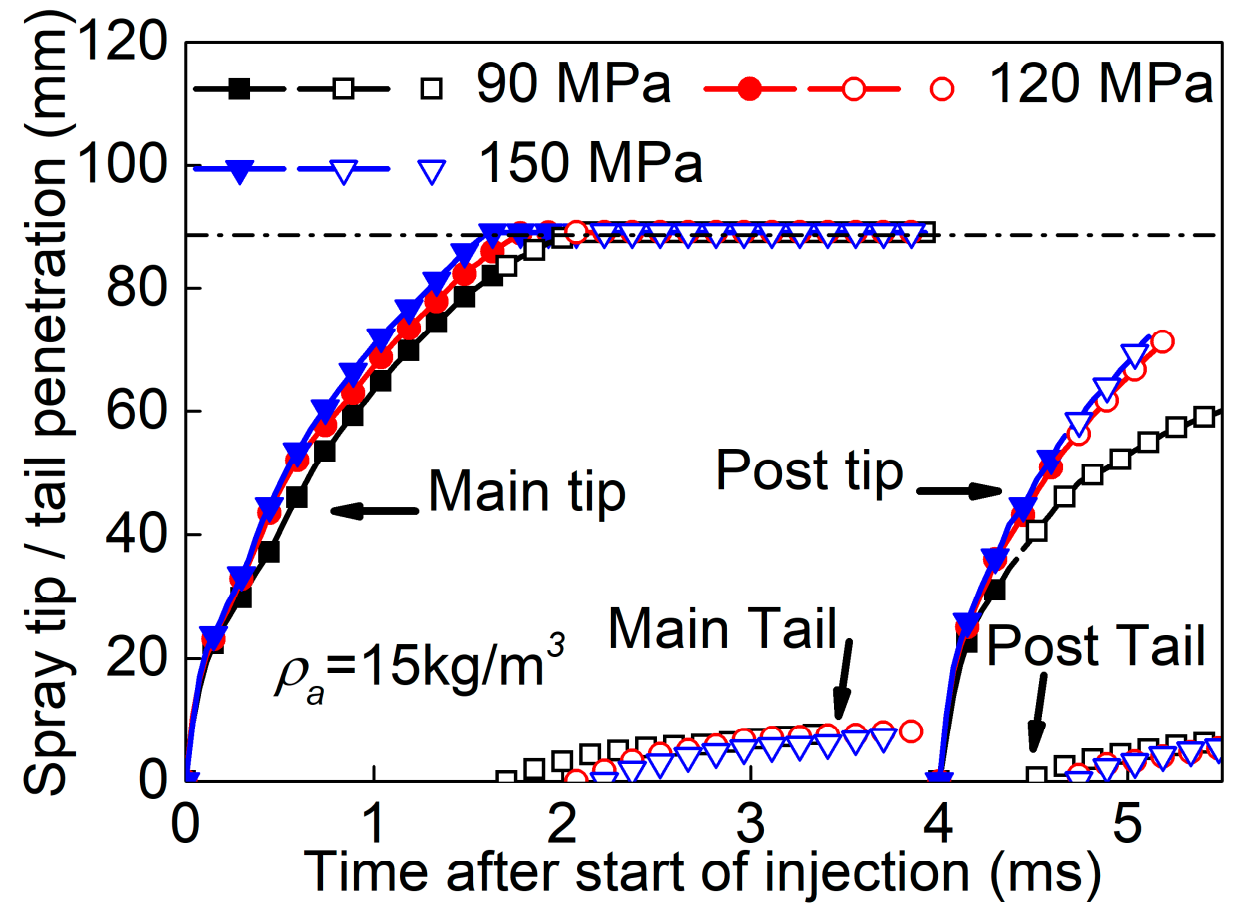

Figure 11. Results of spray tip and tail penetrations when applying the main-post injection strategy under various injection pressures. 
Figure 12 shows the results of spray angle evolvements when applying the main-post injection strategy under the same conditions. For the main spray, the spray angle remains nearly steady after the initial decline, even though it does rise slightly later. According to Gavaises [36], a possible strong turbulence exists in the nozzle hole because of the slight lifts of the needle valve during this time. This may be the reason for the large spray angle in the initial injection phase. Another possible reason can be used to explain this phenomenon. In the initial stage of the injection, the fuel was injected into a relatively stationary air environment, and the air at the nozzle outlet was squeezed and pushed into the radial direction [37]. However, the spray angle remains nearly stable during the later injection stage.

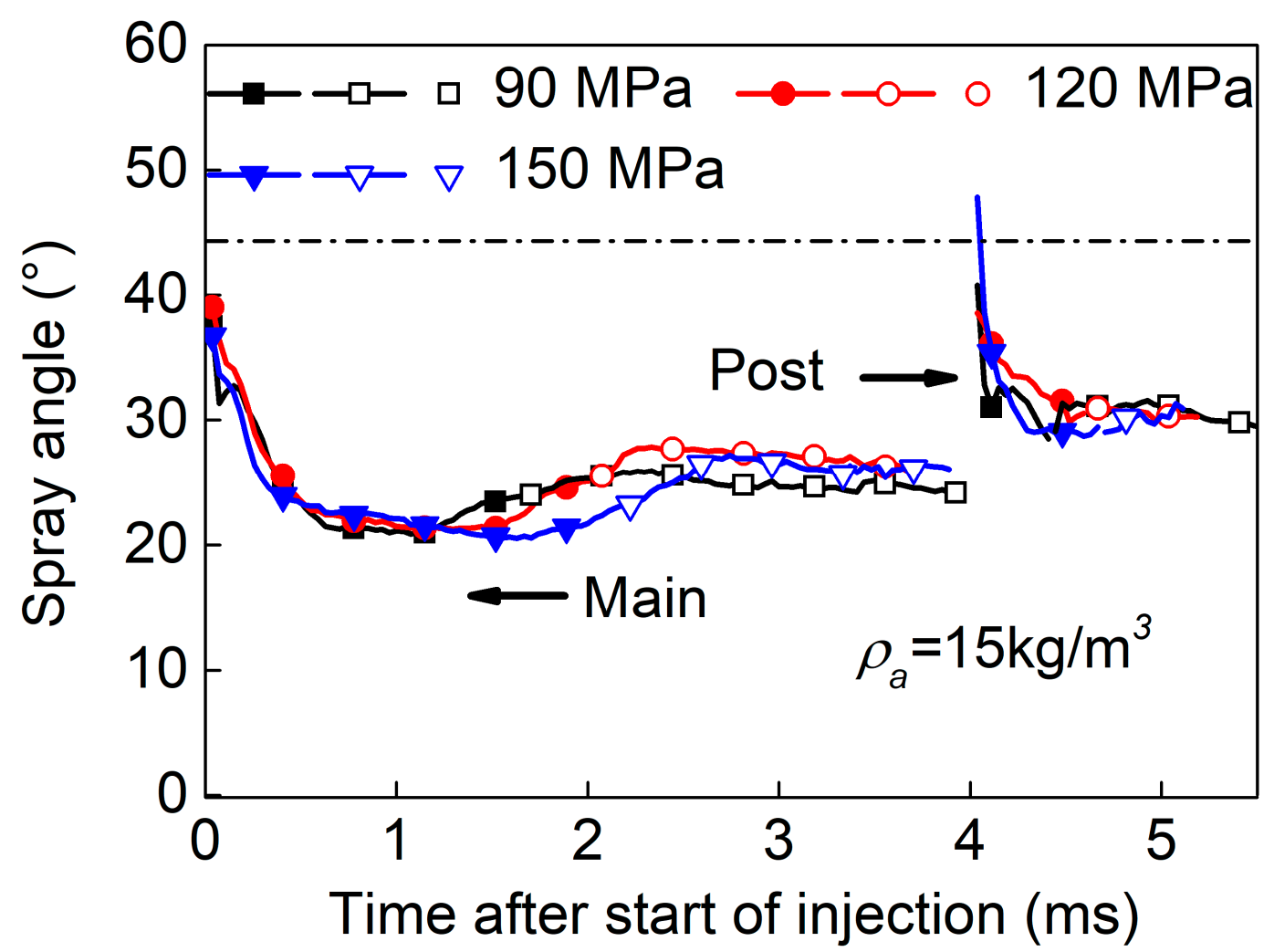

Figure 12. Results of spray angle evolvements when applying the main-post injection strategy under various injection pressures.

Figures 13 and 14 show the results of tip and tail penetrations under various surrounding gas densities at $150 \mathrm{MPa}$ injection pressure. The surrounding gas density was $15 \mathrm{~kg} / \mathrm{m}^{3}, 18 \mathrm{~kg} / \mathrm{m}^{3}$, and $21 \mathrm{~kg} / \mathrm{m}^{3}$, respectively. In general, the trend is that the increased surrounding gas density leads to a slower tip penetration speed. This can be attributed to the increased momentum exchange at higher surrounding gas densities as the fuel droplets are more closely surrounded by environmental gases. It should be noted that the increased ambient density can also reduce the maximum liquid length and better avoid the spray-wall impingement [38].

Figures 15 and 16 illustrate the average spray angle under the same condition. The trend of the spray angle is still that it changes drastically during the initial stage of fuel injection. Subsequently, the spray angle is nearly stable. With the increased surrounding gas density, the spray angle tends to rise, especially before the EOI. 


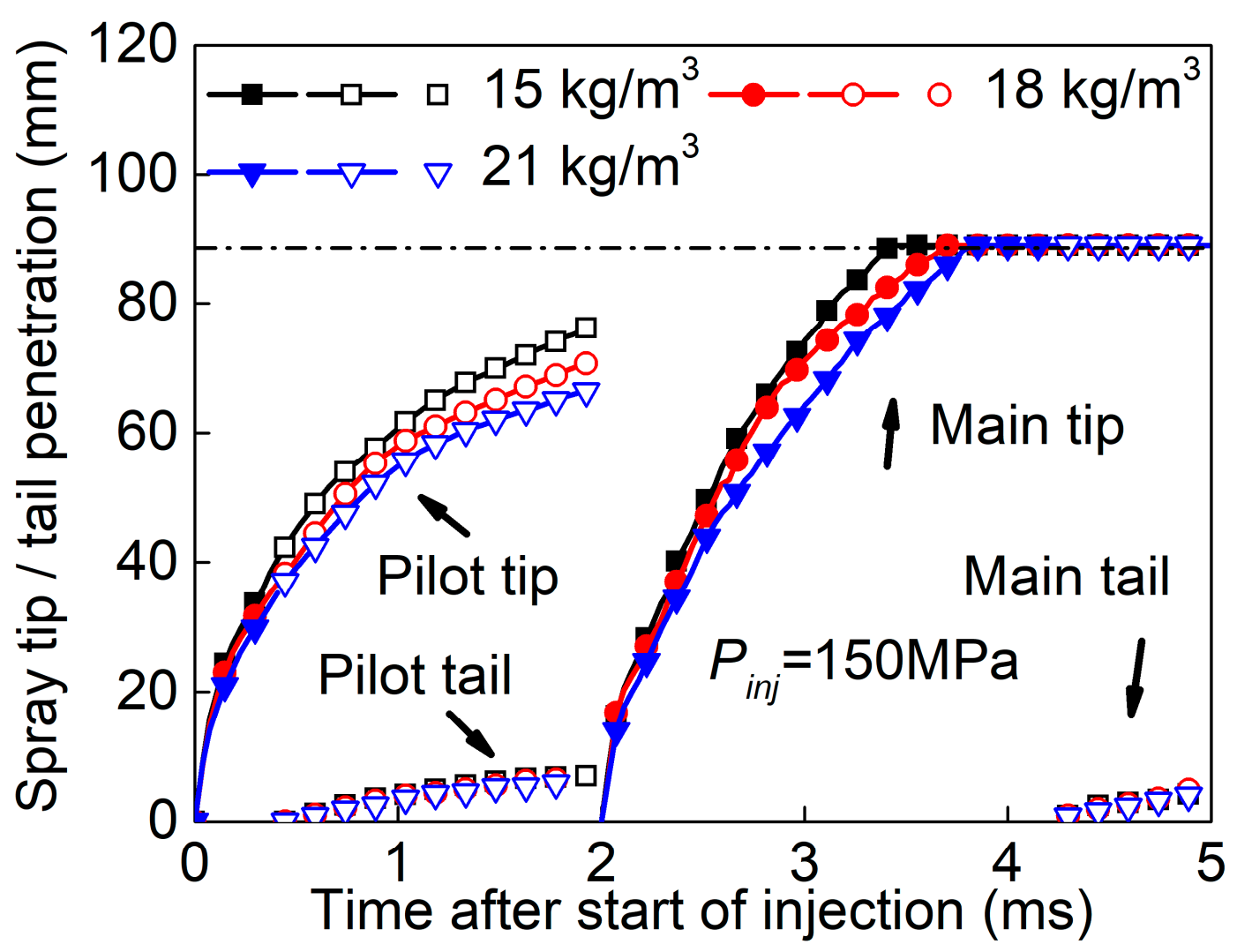

Figure 13. Results of tip and tail penetrations when applying the pilot-main injection strategy under various surrounding gas densities.

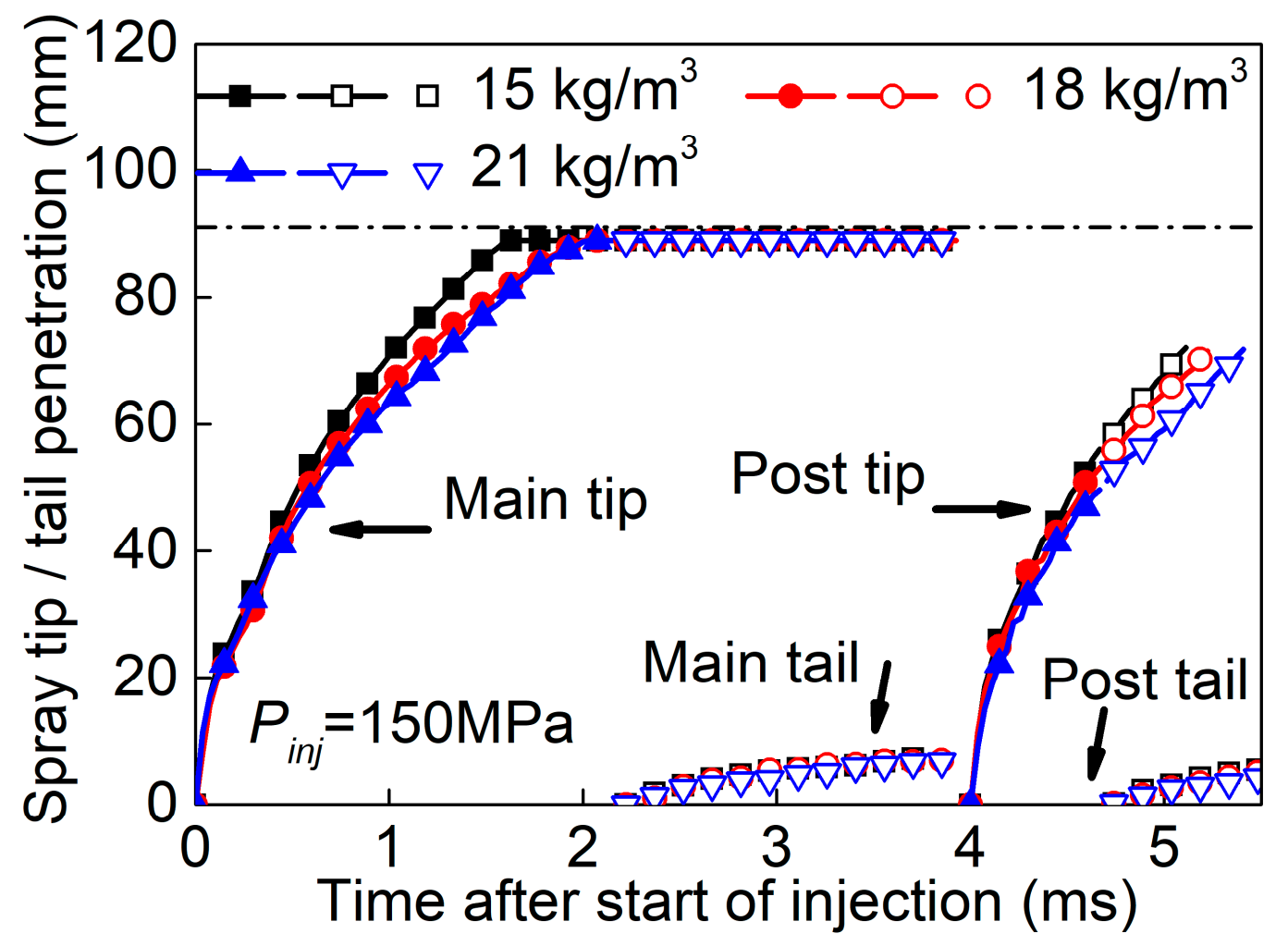

Figure 14. Results of tip and tail penetrations when applying the main-post injection strategy under various surrounding gas densities. 


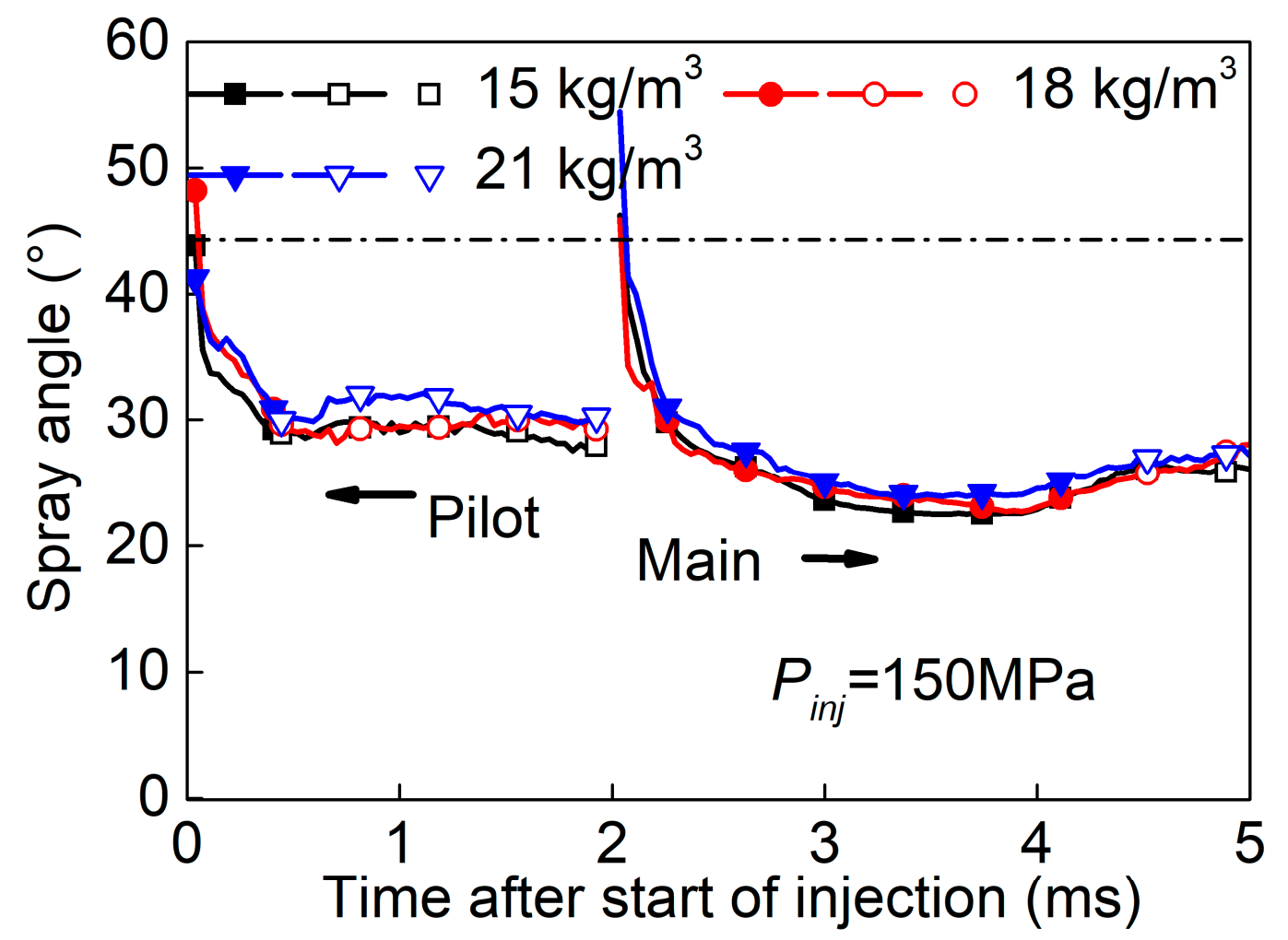

Figure 15. Results of spray angle evolvements when applying the pilot-main injection strategy under various surrounding gas densities.

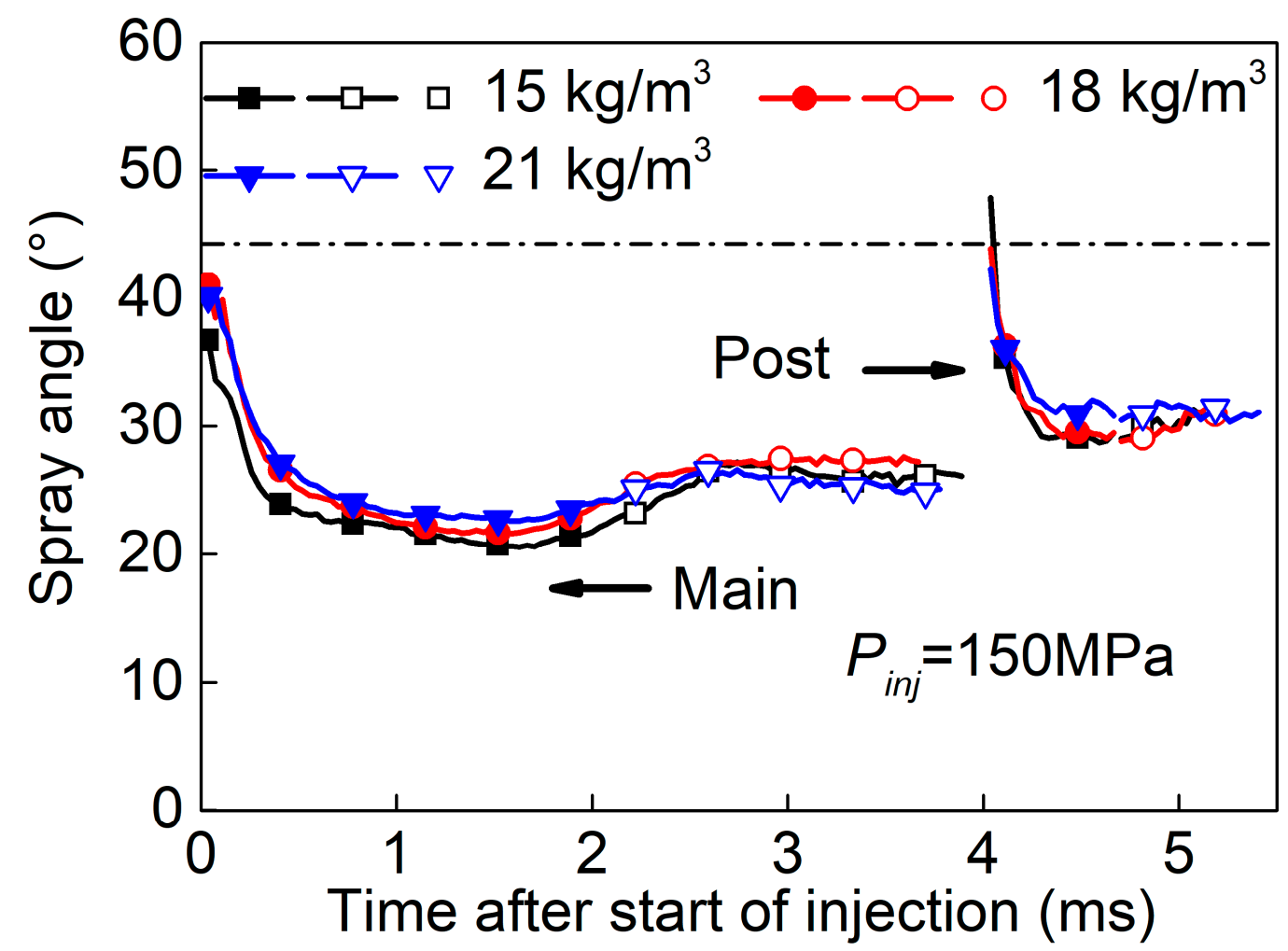

Figure 16. Results of spray angle evolvements with the main-post injection strategy under various surrounding gas densities. 
The black solid line in Figures 17 and 18 show the experimental results for the spray angle under various injection pressures and surrounding gas densities. When the injection pressure is over $120 \mathrm{MPa}$, the spray angle varies little from $120 \mathrm{MPa}$ to $150 \mathrm{MPa}$. When the injection pressure varies from $90 \mathrm{MPa}$ to $120 \mathrm{MPa}$, the spray angle increases. By comparison, the surrounding gas density has a greater effect on the spray angle than the injection pressure. When the surrounding gas density increases, the spray angle rises obviously. Results of the spray angle relationship are in agreement with the previous study [39] described by Inagaki et al., indicating that the spray cone angle should be affected by the injection pressure and surrounding gas density. The specific relationship is expressed as Equation (4):

$$
\alpha=h \cdot\left(\frac{\rho_{a}}{\mu_{f}}\right)^{0.25} \Delta p^{0.18}\left(\frac{l_{n}}{d_{n}}\right)^{-0.14}
$$

where $\alpha$ is the spray angle. $h$ denotes the dimensionless model coefficient. The fuel viscosity is $\mu_{f}$, the unit is Pa.s. The hole length of nozzle is expressed as $l_{n}$, the unit is $\mathrm{m}$.

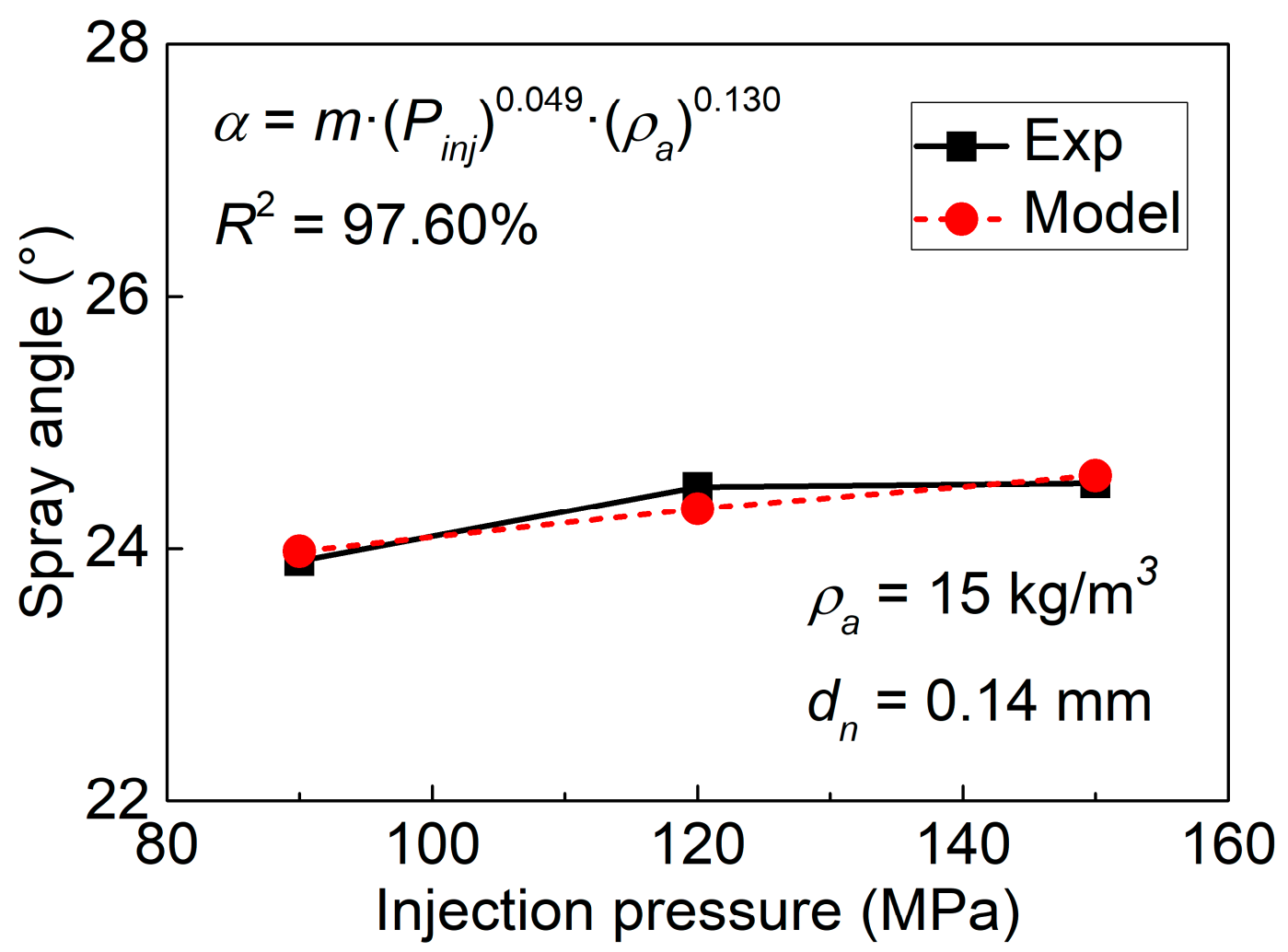

Figure 17. The experimental and predicted results for the spray angle when applying the pilot-main injection strategy under various injection pressures. 


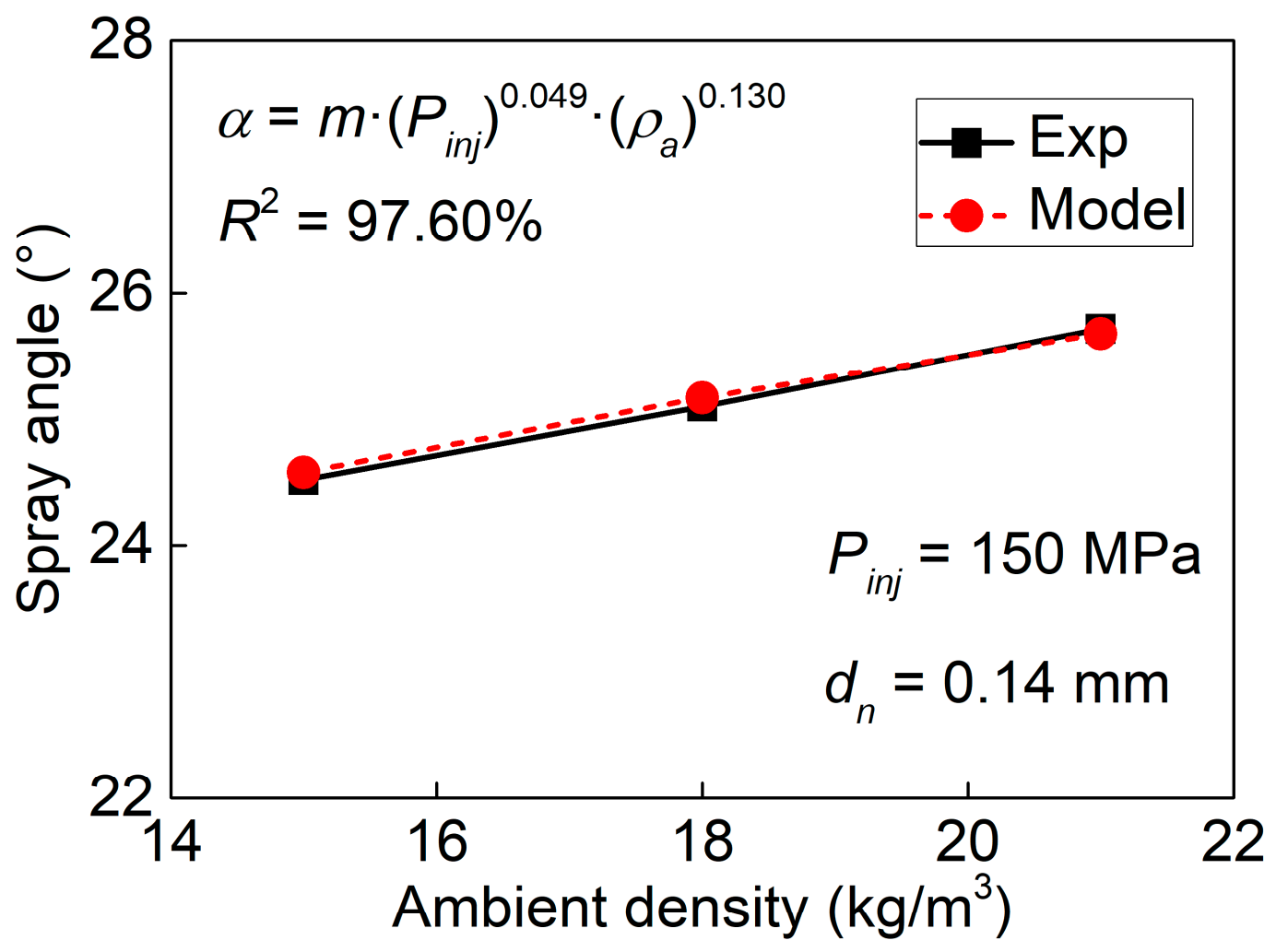

Figure 18. The experimental and predicted results for the spray angle when applying the pilot-main injection strategy under various surrounding gas densities.

The spray angle increases with the increased surrounding gas density, while the increased injection pressure does not cause too much variation in the spray angle. A new correlation for the spray angle is fitted based on the experimental data in this paper to clarify the effects of the injection pressure and ambient density on the spray angle. It is expressed as Equation (5) and shown as the red dotted line in Figures 17 and 18:

$$
\alpha=m \cdot\left(P_{\text {inj }}\right)^{0.049} \cdot\left(\rho_{a}\right)^{0.130}
$$

where $m$ is the mass correlation coefficient, $P_{i n j}$ is the injection pressure, and $\rho_{a}$ is the surrounding gas density. The correlation coefficient $R^{2}$ of this model is nearly to $97.60 \%$, which indicates that it shows good predictability of the spray angle.

For the entire spray area, the mean equivalent ratio of fuel to air, as symbolized by $\phi$, can be calculated according to Equation (6):

$$
\phi(t)=A F_{\text {stoich }} \frac{m_{f}(t)}{m_{a}(t)}
$$

where $m_{f}(t)$ represents the total fuel mass, in $\mathrm{kg} . m_{a}(t)$ is the total air mass, in $\mathrm{kg} . t$ is the time, in seconds. These parameters can be obtained according to the following relationships given as Equation (7):

$$
\left\{\begin{array}{c}
0<\mathrm{t} \leq t_{i} \\
m_{f}(t)=\rho_{f} A_{n} u_{i} t \\
m_{a}(t)=\rho_{a}\left(V(t)-A_{n} u_{i} t\right) \\
t_{i}<t \\
m_{f}(t)=\rho_{f} A_{n} u_{i} t_{i} \\
m_{a}(t)=\rho_{a}\left(V(t)-A_{n} u_{i} t_{i}\right)
\end{array}\right.
$$


where $t_{i}$ is the duration of fuel injection, in seconds. $\rho_{f}$ is the fuel density, in $\mathrm{kg} / \mathrm{m}^{3} . A_{n}$ is the area of nozzle hole, in $\mathrm{m}^{2} . u_{i}$ represents the fuel injection rate, in $\mathrm{m} / \mathrm{s} . \rho_{a}$ is the surrounding gas density, in $\mathrm{kg} / \mathrm{m}^{3} . V(t)$ is the volume of spray, in $\mathrm{m}^{3}$, which can be expressed as Equation (8):

$$
V(t)=\frac{\pi}{3}\left(S_{L}(t)\right)^{3}(\tan \theta(t))^{2} \frac{(1+2 \tan \theta(t))}{(1+\tan \theta(t))^{3}}
$$

Here, $A F_{\text {stoich }}$ is taken as 14.3 .

Figure 19 shows the measured spray length and the calculated equivalent ratio of fuel to air when applying the pilot-injection strategy. Similarly, results before EOI were plotted with solid square symbols while the hollow symbols were shown for the results after EOI. The test conditions are the $0.14 \mathrm{~mm}$ diameter of nozzle, the environmental density was set as $21 \mathrm{~kg} / \mathrm{m}^{3}$, and the injection pressure was $150 \mathrm{MPa}$. The spray length refers to the right half of the figure. The results show that the spray length continues to increase throughout the injection process, which results in a growing volume throughout the process. The equivalent ratio of fuel to air refers to the left half of the figure. The results show a trend that the equivalent ratio of fuel to air decreases with time. This is attributed to the increase in the spray volume. This phenomenon is real and dependable, as seen in similar results by Musculus et al. [40]. It is worth noting that there is a sudden change after a short delay in the air-fuel ratio at EOI. This is created by a slightly increased injection rate at the end of the injection because of the characteristics of the injector.

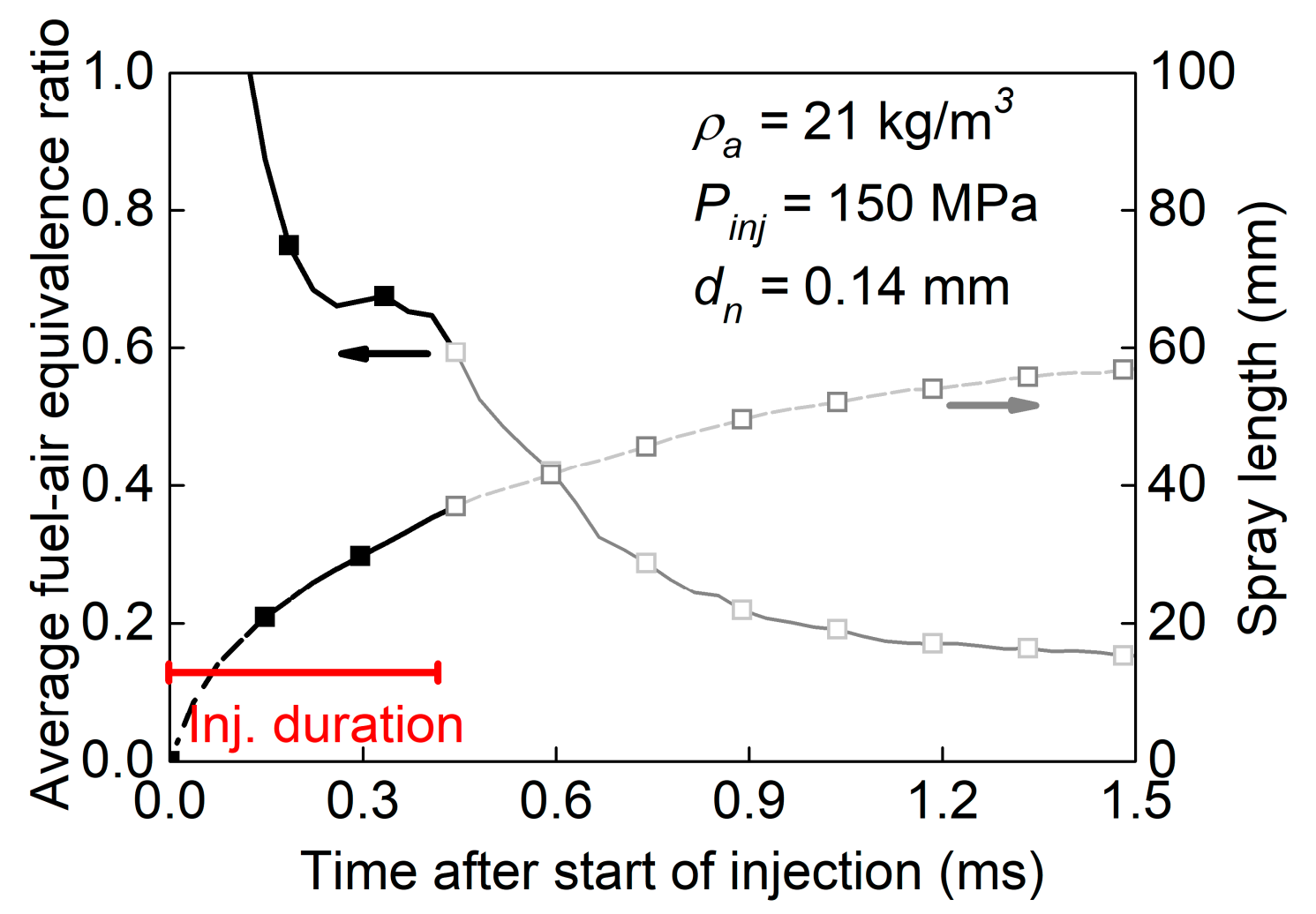

Figure 19. The spray length and equivalent ratio of fuel to air when applying the pilot-injection strategy.

\subsection{Effect of Split-Injection on Spray Tip Penetration}

Figure 20 displays the comparing results of spray tip penetration between the first-splitted spray and second-splitted spray under various injection pressure. The environmental density is $15 \mathrm{~kg} / \mathrm{m}^{3}$, and the injection pressure is $90 \mathrm{MPa}, 120 \mathrm{MPa}$ and $150 \mathrm{MPa}$, respectively. In order to study the effect of split-injection, the two main injection events under the two injection strategies were compared. By studying the tip penetration of the two main injection events, the effect of split-injection on the 
spray can be clarified. The tip penetration of the main injection event when applying the main-post strategy was taken as the "first spray", shown in red line in Figure 16, and the tip penetration of the main injection event when applying the pilot-main strategy was taken as the "second spray", shown in blue. It can be seen that the tip penetration rate of the second spray is slower than that of the first spray at the beginning stage of the entire injection period, but it is significantly higher than the first spray at the later stage. This is because the tip of the second spray will catch up with the first one and hit the tail of it at the beginning stage of the second injection, resulting in a decreased penetration for the second spray. At the later stage of injection, the gas distribution created by the first spray will reduce the resistance of the second spray, resulting in a speed up of the second spray. Naturally, the fuel injected in the later stage has a faster speed, so it catches up with the fuel injected in front of it if the dwell time is short enough. Lacoste et al. [41] reported the same view that as long as the fuel injection continues, the penetration rate should have an upward trend.

Figure 21 shows the comparison of the results of the spray tip penetration between the first spray and second spray under various surrounding gas densities. The surrounding gas density plays a great role on the atomization and entrainment of the spray, which, in turn, determines the distribution of the spray concentration field. Therefore, the spray characteristics will change correspondingly. The injection pressure here remains at $150 \mathrm{MPa}$ and the surrounding gas density is $15 \mathrm{~kg} / \mathrm{m}^{3}, 18 \mathrm{~kg} / \mathrm{m}^{3}$, $21 \mathrm{~kg} / \mathrm{m}^{3}$, respectively. The "first spray" and the "second spray" represent the main injection event of the main-post strategy and pilot-main strategy, respectively. The results show a similar trend with the previous results under various injection pressure. The second spray is also slower than the first spray at the beginning stage and higher than the first one at the later stage, especially when the surrounding gas density is higher than $21 \mathrm{~kg} / \mathrm{m}^{3}$. Still, the collisions from the tip flow of the second spray to the tail flow of first one results in a decrease in the penetration rate of the second spray at the beginning of the injection. It can be expected that the injection dwells will have a significant influence on the penetration rate of the second spray. If the dwell time is too short, it will likely increase the collision between the tail flow and tip flow, influencing the spray mixture formation processes of the second spray. With the collision between droplets, the initial size of the droplets will increase again. At the later stage of the entire injection period, however, the pressure inside the common rail and the nozzle sac dropped slightly, meaning the actual injection pressure at the second injection was slightly lower than that at the first injection. Nevertheless, with the further spray development, an acceleration of the second spray appears, indicating that the distribution of the gas environment produced by the first spray reduces the resistance of the second spray. 

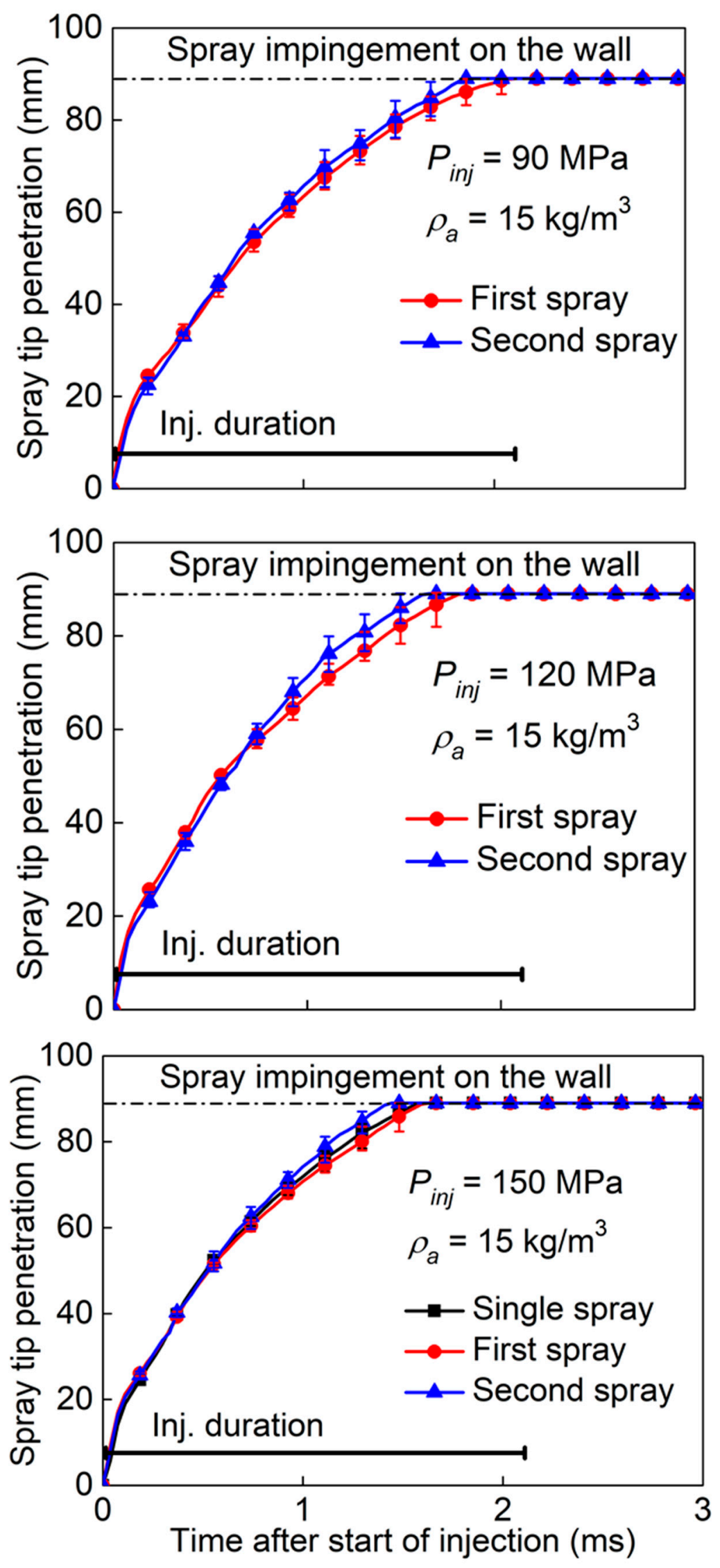

Figure 20. Comparing results of spray tip penetration between the first spray and second spray under various injection pressure. 

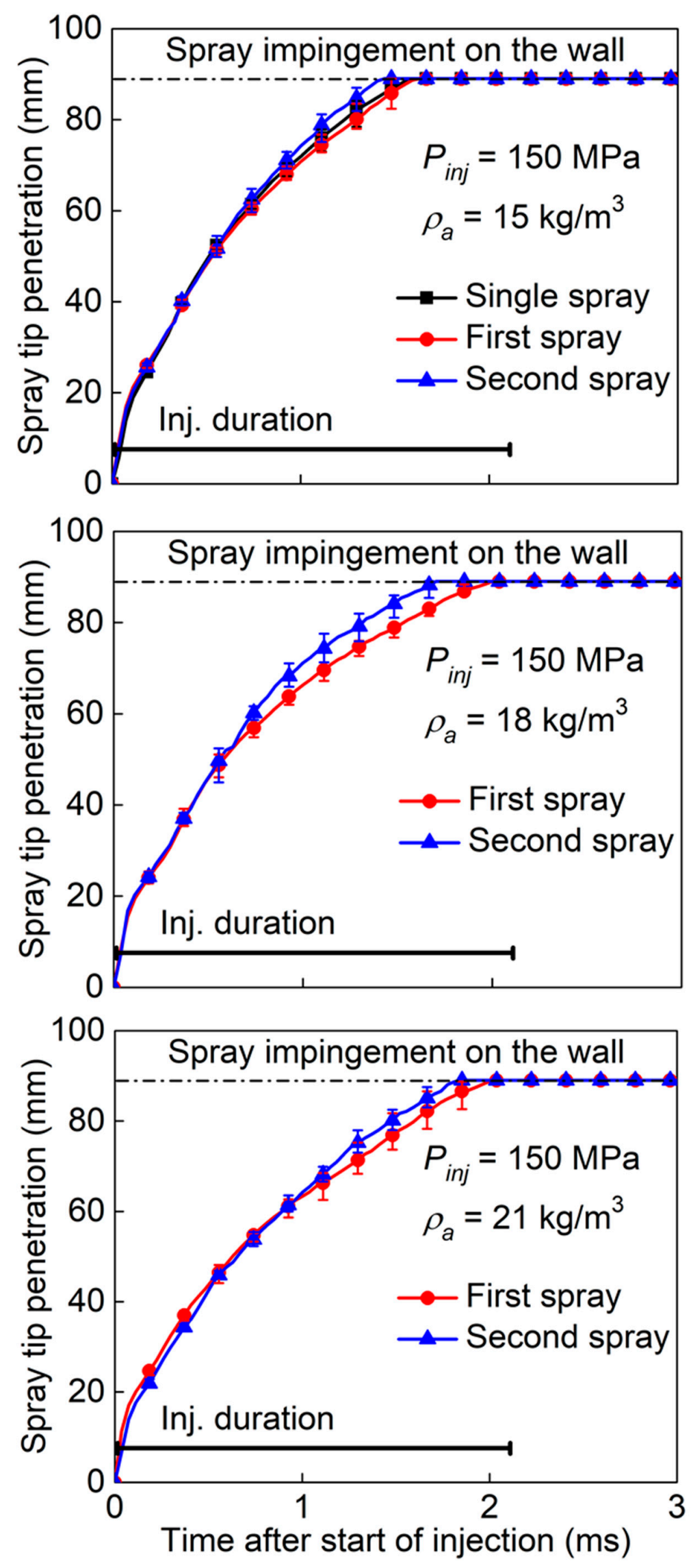

Figure 21. Comparing results of spray tip penetration between the first spray and second spray under various surrounding gas densities. 


\section{Summary and Conclusions}

In this work, the developments of spray tip and tail penetrations as well as the evolvements of the spray angle were explored by applying the pilot-main injection strategy and main-post injection strategy. The influences of the injection pressure and surrounding gas density on two split injection strategies have been investigated. The conclusions can be summarized as follows:

The study of split injection should pay attention to the penetration of the spray tip and tail. Injection pressure and surrounding gas density have an obvious influence on the spray tip penetration rate. The penetration rate of tip spray increases with the increased injection pressure, while it declines with the increased surrounding gas density. The tail of the spray penetration develops slower than the tip, resulting in the significant stretch of the spray.

The spray angle increases with the increased surrounding gas density, while the increased injection pressure does not cause too much variation in spray angle. A new correlation for the spray angle is fitted based on the experimental data in this paper to clarify the effects of the injection pressure and ambient density on the spray angle.

The mean fuel air equivalence ratio decreases as the spray develops. Additionally, there is a transition phenomenon that exists in the descent progress for the calculated equivalent ratio.

There is an interaction between the split-injected sprays that will affect the mixture formation process. The tip penetration of the second spray is slower than the first one at the beginning stage of the split-injected injection, but it is significantly higher than the first one at the later stage. The gas distribution created by the first spray, at the end stage of injection, will reduce the resistance of the second spray, resulting in a speed up of the second spray.

Author Contributions: T.L. and G.W. designed experiments; G.W. and X.Z. carried out experiments; G.W. and X.Z. analyzed experimental results. X.Z. developed analysis tools. G.W. wrote the manuscript.

Funding: The authors disclosed receipt of the following financial support for the research, authorship, or publication of this article: This study was supported by the National Natural Science Foundation of China (51776125).

Conflicts of Interest: The author(s) declared no potential conflicts of interest with respect to the research, authorship, and/or publication of this article.

\section{Nomenclature}

$\begin{array}{llll}A F_{\text {stoich }} & \text { Theoretical ratio of air to fuel } & \rho_{a} & \text { Surrounding gas density }\left(\mathrm{kg} / \mathrm{m}^{3}\right) \\ d_{n} & \text { Nozzle hole diameter }(\mathrm{m}) & \rho_{f} & \text { Fuel density }\left(\mathrm{kg} / \mathrm{m}^{3}\right) \\ l_{n} & \text { Nozzle hole length }(\mathrm{m}) & A_{s, S / 2} & \text { Spray area of half spray length }\left(\mathrm{m}^{2}\right) \\ m_{a} & \text { Surrounding gas mass of spray area }(\mathrm{kg}) & A_{S} & \text { Spray area }\left(\mathrm{m}^{2}\right) \\ m_{f} & \text { Fuel mass of spray area }(\mathrm{kg}) & A_{n} & \text { Nozzle hole area }\left(\mathrm{m}^{2}\right) \\ m & \text { Mass correlation coefficient }(-) & h & \text { Model constant } \\ S_{L} & \text { Spray length }(\mathrm{m}) & \Delta P & \text { Pressure difference between } \\ S_{t a i l} & \text { Spray penetration in tail position }(\mathrm{m}) & H & \text { environment and injection }(\mathrm{Pa}) \\ S_{t i p} & \text { Spray penetration in tip position }(\mathrm{m}) & T & \text { The fore edge of the spray region } \\ T & \text { Time after the start of injection }(\mathrm{s}) & O & \text { The upmost point in the spray image } \\ t_{i} & \text { Fuel injection duration }(\mathrm{s}) & \alpha & \text { Nozzle hole outlet position } \\ u_{i} & \text { Injection rate of fuel }(\mathrm{m} / \mathrm{s}) & \text { EOI } & \left.\text { Spray angle }{ }^{\circ}\right) \\ V(t) & \text { Transient spray volume at time } \mathrm{t}\left(\mathrm{m}^{3}\right) & \mathrm{NOx} & \text { End of injection } \\ \Phi & \text { Mean equivalent ratio of fuel to air } & \text { CO } & \text { Carbon monoxides } \\ \mu_{f} & \text { Viscosity of fuel }(\mathrm{Pa} \cdot \mathrm{s}) & \mathrm{UHC} & \text { Unburned hydrocarbon } \\ \theta & \text { Fifty percent angle of spray }\left(^{\circ}\right) & \text { SMD } & \text { Sauter mean diameter } \\ P_{i n j} & \text { Injection pressure }(\mathrm{MPa}) & \text { CMOS } & \text { Complementary metal oxide } \\ & & & \text { semiconductor }\end{array}$




\section{References}

1. Park, S.H.; Yoon, S.H.; Lee, C.S. Effects of multiple-injection strategies on overall spray behavior, combustion, and emissions reduction characteristics of biodiesel fuel. Appl. Energy 2011, 88, 88-98. [CrossRef]

2. Kim, G.; Moon, S.; Lee, S. Numerical Analysis of the Combustion and Emission Characteristics of Diesel Engines with Multiple Injection Strategies Using a Modified 2-D Flamelet Model. Energies 2017, 10, 1292. [CrossRef]

3. MacMillan, D.J. Influences on the Cold Start Behaviour of a Diesel Engine at Reduced Compression Ratio. Ph.D. Thesis, University of Nottingham, Nottingham, UK, 2009.

4. Wang, Z.; Jiang, C.; Xu, H.; Wyszynski, M. Macroscopic and microscopic characterization of diesel spray under room temperature and low temperature with split injection. Fuel Process. Technol. 2016, 142, 71-85. [CrossRef]

5. Carlucci, P.; Ficarella, A.; Laforgia, D. Effects on combustion and emissions of early and pilot fuel injections in diesel engines. Int. J. Engine Res. 2005, 6, 43-60. [CrossRef]

6. Lee, C.; Chung, J.; Lee, K. Emission Characteristics for a Homogeneous Charged Compression Ignition Diesel Engine with Exhaust Gas Recirculation Using Split Injection Methodology. Energies 2017, 10, 2146. [CrossRef]

7. Moiz, A.; Ameen, M.; Lee, S.; Som, S. Study of soot production for double injections of n-dodecane in CI engine-like conditions. Combust. Flame 2016, 173, 123-131. [CrossRef]

8. Mendez, S.; Thirouard, B. Using Multiple Injection Strategies in Diesel Combustion: Potential to Improve Emissions, Noise and Fuel Economy Trade-Off in Low CR Engines. SAE Int. J. Fuels Lubr. 2009, 1, 662-674. [CrossRef]

9. Kourosh, K. Characterisation of Multiple-Injection Diesel Sprays at Elevated Pressures and Temperatures. Ph.D. Thesis, School of Engineering in University, Brighton, UK, 2007.

10. Han, D.; Li, K.; Duan, Y.; Lin, H.; Huang, Z. Numerical study on fuel physical effects on the split injection processes on a common rail injection system. Energy Convers. Manag. 2017, 134, 47-58. [CrossRef]

11. Hadadpour, A.; Jangi, M.; Bai, X. Jet-jet interaction in multiple injections: A large-eddy simulation study. Fuel 2018, 234, 286-295. [CrossRef]

12. Yun, H.; Reitz, R. An experimental investigation on the effect of post-injection strategies on combustion and emissions in the low-temperature diesel combustion regime. J. Eng. Gas Turbines Power-Trans. Asme 2007, 129, 279-286. [CrossRef]

13. Bobba, M.; Musculus, M.; Neel, W. Effect of post injections on in-cylinder and exhaust soot for low-temperature combustion in a heavy-duty diesel engine. SAE Int. J. Eng. 2010, 3, 496-516. [CrossRef]

14. Arregle, J.; Pastor, J.; Lopez, J.; Garcia, A. Insights on postinjection-associated soot emissions in direct injection diesel engines. Combust. Flame 2008, 154, 448-461. [CrossRef]

15. Hu, B.; Musculus, M.; Oefelein, J. The influence of large-scale structures on entrainment in a decelerating transient turbulent jet revealed by large eddy simulation. Phys. Fluids 2012, 24, 045106. [CrossRef]

16. Huang, S.; Deng, P.; Huang, R.; Wang, Z.; Ma, Y.; Dai, H. Visualization research on spray atomization, evaporation and combustion processes of ethanol-diesel blend under LTC conditions. Energy Convers. Manag. 2015, 106, 911-920. [CrossRef]

17. Wang, Z.; Xu, H.; Jiang, C. Experimental study on microscopic and macroscopic characteristics of diesel spray with split injection. Fuel 2016, 174, 140. [CrossRef]

18. Wang, Z.; Ding, H.; Wyszynski, M. Experimental study on diesel fuel injection characteristics under cold start conditions with single and split injection strategies. Fuel Process. Technol. 2015, 131, 213-222. [CrossRef]

19. Lee, C.; Lee, K.; Reitz, R.; Park, S. Effect of split injection on the macroscopic development and atomization characteristics of a diesel spray injected through a common-rail system. At. Sprays 2006, 16, 543-562. [CrossRef]

20. Ma, S.; Zheng, Z.; Liu, H.; Zhang, Q.; Yao, M. Experimental investigation of the effects of diesel injection strategy on gasoline/diesel dual-fuel combustion. Appl. Energy 2013, 109, 202-212. [CrossRef]

21. Lim, J.; Lee, S.; Min, K. Combustion modeling of split injection in hsdi diesel engines. Combust. Sci. Technol. 2011, 183, 180-201. [CrossRef]

22. Hiroshi, H.; Motoo, O.; Toshikazu, K. Study on Performance Improvement of DI diesel Engine with pilot injection Method. SAE Int. J. Eng. 1991. Available online: https://saemobilus.sae.org/content/912462 (accessed on 30 October 2019). 
23. Imperato, M.; Kaario, O.; Sarjovaara, T. Split fuel injection and Miller cycle in a large-bore engine. Appl. Energy 2016, 162, 289. [CrossRef]

24. Zhuang, J.; Qiao, X.; Bai, J. Effect of injection-strategy on combustion, performance and emission characteristics in a DI-diesel engine fueled with diesel from direct coal liquefaction. Fuel 2014, 121, 141. [CrossRef]

25. Yao, M.; Wang, H.; Zheng, Z. Experimental study of n-butanol additive and multi-injection on HD diesel engine performance and emissions. Fuel 2010, 89, 2191. [CrossRef]

26. Chen, S.K. Simultaneous reduction of NOx and particulate emissions by using multiple injections in a small diese engine. SAE Trans. 2000, 109, 2127-2136. [CrossRef]

27. Han, Z.; Uludogan, A.; Hampson, J. Mechanism of soot and NOx emission reduction using multiple-injection in a diesel engine. SAE Trans. 1996, 105, 837-852. [CrossRef]

28. Bosch, W. The Fuel Rate Indicator: A new measuring instrument for display of the characteristics of individual injection. SAE Tech. Pap. 1966. [CrossRef]

29. Zhou, X.; Li, T.; Lai, Z.; Wang, B. Scaling fuel sprays for different size diesel engines. Fuel 2018, 225, 358-369. [CrossRef]

30. Zhou, X.; Li, T.; Lai, Z.; Wei, Y. Modeling diesel spray tip and tail penetrations after end-of-injection. Fuel 2019, 237, 442-456. [CrossRef]

31. Naber, D.; Siebers, L. Effects of gas density and vaporization on penetration and dispersion of diesel sprays. SAE Trans. 2000, 105, 82-111. [CrossRef]

32. Takamura, A.; Ohta, T. Fukushima, S.; Kamimoto, T. A study on precise measurement of diesel fuel injection rate. SAE Tech. Pap. 1992. [CrossRef]

33. Arai, M.; Amagai, K. Dynamic behavior of multi-stage injection diesel spray. SAE Tech. Pap. 1997. [CrossRef]

34. Li, T.; Nishida, K.; Zhang, Y.; Hiroyasu, H. Effect of split injection on stratified charge formation of direct injection spark ignition engines. Int. J. Engine Res. 2007, 8, 205-219. [CrossRef]

35. Doudou, A. Turbulent flow study of an isothermal diesel spray injected by a common rail system. Fuel 2005, 84, 287-298. [CrossRef]

36. Gavaises, M.; Andriotis, A. Cavitation inside multi-hole injectors for large diesel enginesand its effect on the near-nozzle spray structure. SAE Tech. Pap. 2006. [CrossRef]

37. Taşkiran, O.; Ergeneman, M. Experimental study on diesel spray characteristics and auto ignition process. J. Combust. 2011, 3, 1-20. [CrossRef]

38. Zhou, X.; Li, T.; Wei, Y.; Wu, S. Scaling spray combustion processes in marine low-speed diesel engines. Fuel 2019, 258, 116133. [CrossRef]

39. Inagaki, K.; Mizuta, J.; Kawamura, K. Theoretical study on spray design for small-bore diesel engine. SAE Tech. Pap. 2016. [CrossRef]

40. Musculus, M.; Lachaux, T.; Pickett, L. End-of-injection over-mixing and unburned hydrocarbon emissions in low-temperature-combustion diesel engines. SAE Tech. Pap. 2007. [CrossRef]

41. Lacoste, J. PDA characterisation of dense diesel sprays using a common rail injection system. SAE Trans. 2003, 112, 2074-2085. [CrossRef]

(C) 2019 by the authors. Licensee MDPI, Basel, Switzerland. This article is an open access article distributed under the terms and conditions of the Creative Commons Attribution (CC BY) license (http://creativecommons.org/licenses/by/4.0/). 